\title{
Bradyrhizobium japonicum IRAT FA3 Alters Arabidopsis thaliana Root Architecture via Regulation of Auxin Efflux Transporters PIN2, PIN3, PIN7, and ABCB19
}

\author{
Mercedes M. Schroeder, Melissa Y. Gomez, Nathan McLain, and Emma W. Gachomo ${ }^{\dagger}$ \\ Department of Microbiology and Plant Pathology, University of California-Riverside, Riverside, CA 92521, U.S.A.
}

Accepted 16 November 2021.

\begin{abstract}
Beneficial rhizobacteria can stimulate changes in plant root development. Although root system growth is mediated by multiple factors, the regulated distribution of the phytohormone auxin within root tissues plays a principal role. Auxin transport facilitators help to generate the auxin gradients and maxima that determine root structure. Here, we show that the plant-growth-promoting rhizobacterial strain Bradyrhizobium japonicum IRAT FA3 influences specific auxin efflux transporters to alter Arabidopsis thaliana root morphology. Gene expression profiling of host transcripts in control and $B$. japonicum-inoculated roots of the wild-type $A$. thaliana accession Col-0 confirmed upregulation of PIN2, PIN3, PIN7, and $A B C B 19$ with $B$. japonicum and identified genes potentially contributing to a diverse array of auxinrelated responses. Cocultivation of the bacterium with lossof-function auxin efflux transport mutants revealed that $B$. japonicum requires $P I N 3, P I N 7$, and $A B C B 19$ to increase lateral root development and utilizes $P I N 2$ to reduce primary root length. Accelerated lateral root primordia production due to $B$. japonicum was not observed in single pin3, pin 7 , or abcb19 mutants, suggesting independent roles for PIN3, $P I N 7$, and $A B C B 19$ during the plant-microbe interaction. Our work demonstrates $B$. japonicum's influence over host transcriptional reprogramming during plant interaction with this beneficial microbe and the subsequent alterations to root system architecture.
\end{abstract}

Keywords: auxin transport, bacteria-plant symbiosis, lateral root primordia, lateral roots, plant-growth-promoting rhizobacteria, plant hormones, primary root

Plant-growth-promoting rhizobacteria (PGPR) are soil microorganisms that stimulate plant growth and can be utilized in crop agriculture to increase yield and provide abiotic and biotic protection (Backer et al. 2018; Gachomo et al. 2014; Ryu et al. 2003).

${ }^{\dagger}$ Corresponding author: E. W. Gachomo; emma.gachomo@ucr.edu

Funding: Support was provided by the University of California-Riverside (startup funds to E. W. Gachomo).

*The $\boldsymbol{e}$-Xtra logo stands for "electronic extra" and indicates that supplementary materials are published online.

The author(s) declare no conflict of interest. distributed under the CC BY-NC-ND 4.0 International license.
Among soil bacteria, the Bradyrhizobium genus is the most ubiquitous (Shah and Subramaniam 2018). Because these bacteria are such a major component of the soil microbiota, greater understanding of mutualistic Bradyrhizobium microbe-plant interactions has the potential to increase plant production and benefit agriculture.

PGPR are often associated with alterations to root morphology and metabolism of various phytohormones (Loper and Schroth 1986; Ryu et al. 2003; Zamioudis et al. 2013). Specifically, Bradyrhizobium japonicum strains are known to produce plant hormones and hormone precursors, including those associated with major auxin, ethylene, or abscisic acid plant signaling pathways (Boiero et al. 2007; Hodge et al. 2009). Stimulation of root growth by PGPR may be the result of volatile or diffusible compounds, produced by the microbes, that serve as phytohormones, precursors, or other cues that affect host cell genetic reprogramming and consequential growth promotion (Shi et al. 2010; Spaepen et al. 2007).

Previous research has established the key roles of auxin synthesis, transport, and signaling in root growth (Du and Scheres 2018; Hodge et al. 2009; Overvoorde et al. 2010). Auxin, predominantly found as indole-3-acetic acid (IAA) in plants, is transported between plant cells and tissues, resulting in a regulated distribution that directs plant development (Petrásek and Friml 2009). In its protonated form, IAA (IAAH) can diffuse through the plasma membrane but, in its anionic form, $\mathrm{IAA}^{-}$is actively transported by auxin influx facilitators (Delbarre et al. 1996). Inside the neutral cellular environment (approximately $\mathrm{pH}$ 7), anionic $\mathrm{IAA}^{-}$predominates, requiring auxin efflux carriers to transport it out of the cell (Ng et al. 2015; Zažímalová et al. 2010). Plasma membrane (PM) location of influx and efflux transporters decides directionality of auxin ion movement but polar localization of the efflux carrier proteins can change as internal or environmental cues direct or redirect auxin flow through plant tissues (Geisler et al. 2017; Kleine-Vehn et al. 2008; Tanaka et al. 2006). Auxin transport determines auxin distribution, localized accumulation, and gradient formation in the plant (Benková et al. 2003; Grieneisen et al. 2007; Overvoorde et al. 2010). The auxin efflux system and auxin feedback mechanisms are essential for maintaining these auxin gradients and constructing the root system architecture (Benková et al. 2003; Tanaka et al. 2006). Root polar auxin transport takes place as IAA moves from cell to cell through root tissues. IAA acropetal flux (toward the root tip) predominantly travels through the stele, endodermis, and cortex, while major basipetal transport (from the root tip toward the base) occurs in the lateral root cap, epidermis, and cortex (Jozef et al. 2017; Laskowski and ten Tusscher 2017; Leyser 2006; Muday and DeLong 2001). 
Two groups of auxin efflux carriers are found in the PINFORMED (PIN) protein family and ATP-binding cassette subfamily $\mathrm{B}$ (ABCB)-type members of the multidrug resistance/ phosphoglycoprotein (ABCB/MDR/PGP) protein family (Noh et al. 2001; Petrásek and Friml 2009; Zažímalová et al. 2010). PIN proteins transport auxin across cellular membranes and have various functional roles in shoots and roots (Mohanta et al. 2018; Zhang et al. 2020). PINs are redundantly involved in stages of primary root (PR) and lateral root (LR) development (Blilou et al. 2005). Distinct root architecture phenotypes may not be apparent or vary in many single pin mutants but multiple pin gene mutations have shown clear disruptions to PR and LR patterning (Benková et al. 2003; Blilou et al. 2005; Laskowski et al. 2008; Lewis et al. 2011). Among the eight PIN proteins of the model plant Arabidopsis thaliana, PIN1 to PIN4 and PIN6 and PIN7 localize predominantly to the PM in a polar orientation that guides directional auxin flow (Křeček et al. 2009; Zhou and Luo 2018). ABCB4 and ABCB19 (and other ABCBs) are also shoot- and root-expressed intercellular auxin transporters; however, they exhibit mostly nonpolar localization in the PM (Blakeslee et al. 2007; Cho and Cho 2013; Jenness et al. 2020). ABCBs, having more stable and often symmetrical PM distribution, may predominantly regulate cellular auxin homeostasis, while PINs, highly responsive to internal or external signals and with polar PM localization, direct auxin flow to form auxin gradients in root tissues (Cho and Cho 2013). PIN-ABCB interactions and PIN protein turnover have been shown to enhance auxin transport levels or specificity (Blakeslee et al. 2007; Cho and Cho 2013; Geisler et al. 2017).

PIN and ABCB regulation of auxin distribution leads to root system architecture development. PR and LR morphogenesis are determined by auxin transport facilitator maintenance and alterations of auxin gradients, complex subcellular molecular interactions, internal developmental programs, and external stimuli (Sauer and Kleine-Vehn 2019; Tanaka et al. 2006). Auxin increases PR length at very low concentrations but high auxin doses inhibit PR elongation (Simon et al. 2013; Stoeckle et al. 2018; Waidmann et al. 2020). Moreover, auxin is the dominant hormonal regulator of LR development (Cavallari et al. 2021; Fukaki and Tasaka 2009; Overvoorde et al. 2010). LR growth encompasses LR primordia (LRP) initiation and progression, as well as LR emergence and outgrowth; these, together with higher-order LR branching, are the major contributing factors to root system size (Waidmann et al. 2020). LR development can be stimulated by both local and overall auxin increases (Boerjan et al. 1995; Dubrovsky et al. 2008). Root development heavily influenced by PGPR often leads to increases in root system size which can enhance nutrient uptake that supports increases in shoot growth and yield (Bailly et al. 2014; Gachomo et al. 2014; Ryu et al. 2003). Auxin can be one of the major factors produced by PGPR, yet it is likely that additional compounds crosstalk with auxin, in concert with the plant, to promote growth (Asari et al. 2017; Semeradova et al. 2020). Many bradyrhizobia are known for symbiotic associations with plants, inducing nodule formation in legumes. $B$. japonicum IRAT FA3 (B. japonicum) has been shown to promote growth in A. thaliana and maize (Gachomo et al. 2014). We are further characterizing it here to better understand the mechanisms it uses to promote plant development, with emphasis on enhanced lateral root formation, in A. thaliana. By profiling host transcripts in B. japonicuminoculated roots of the wild-type $A$. thaliana accession Columbia (Col-0), we identified genes potentially contributing to a diverse array of auxin-related responses. We used transgenic $A$. thaliana lines with mutations in genes known to have roles in root development and auxin transport to further elucidate auxin pathway points of influence by $B$. japonicum and found four specific auxin efflux transporters to have nonredundant functions required for
B. japonicum-stimulated root growth modification. This work proposes mechanisms by which $B$. japonicum strain IRAT FA3 promotes alterations in $A$. thaliana root architecture.

\section{RESULTS}

\section{B. japonicum stimulates root architecture alterations in A. thaliana.}

B. japonicum strain IRAT FA3 has been shown to increase plant biomass (Gachomo et al. 2014). To closely examine specific root growth responses to $B$. japonicum, bacteria were applied directly to $A$. thaliana seedling roots (cocultivation) grown on agar plates. Inoculation of wild-type (Col-0) plant roots decreased the PR length and increased LR development (Fig. 1). Following 6 days of cocultivation, PR length was significantly reduced by $44.8 \%$ compared with control-treated roots (Fig. 1B). One of the most prominent $B$. japonicum-mediated morphological alterations in the root system architecture was the stimulation of LR formation (Fig. 1). The LR number was significantly higher as early as 2 days postinoculation (dpi) in B. japonicum-inoculated plants. After 8 dpi, the average number of total LR per seedling was $70 \%$ higher than that of the noninoculated plants (Fig. 1C).

\section{B. japonicum produces auxin and activates auxin responses in $A$. thaliana.}

A relationship between IAA accumulation and rhizobacteriastimulated plant growth has been established between certain PGPR and plants (Loper and Schroth 1986; Spaepen et al. 2007). The root phenotype induced by $B$. japonicum is a typical response to auxin (Woodward and Bartel 2005). The increased LR phenotype can be mimicked by the exogenous addition of $1 \mu \mathrm{M}$ naphthalene-1-acetic acid (NAA) or $10 \mu \mathrm{M}$ indole-3-butyric acid (IBA), as seen in our data presented in Supplementary Fig. S1, as well as in previous work (Simon et al. 2013). The auxin compound solvent $0.1 \%$ dimethyl sulfoxide (DMSO) did not appear to affect $B$. japonicum's ability to induce LR production (Supplementary Fig. S1). Serving as a potential negative control for $B$. japonicum, we also tested $B$. diazoefficiens (previously B. japonicum) strain USDA 110 LI with $A$. thaliana. USDA 110 LI did not induce increased LR production in Col-0 plants in our LR counting assay, and its IAA production in culture was undetectable (Supplementary Fig. S2). USDA 110 LI, a USDA 110 derivative, is considered an ineffective strain because it lacks symbiotic $\mathrm{N}_{2}$-fixation ability (Kuykendall and Elkan 1976).

Tryptophan is a precursor of IAA in higher plants that has been found in root exudates (Kamilova et al. 2006; Vacheron et al. 2013). IAA can be synthesized from tryptophan by some rhizobacteria (Kamilova et al. 2006; Spaepen et al. 2007). We quantified the actual (no L-tryptophan addition) and potential (2 mM L-tryptophan added) production of IAA by B. japonicum grown in Luria-Bertani (LB) broth using spectrophotometry (Gordon and Weber 1951). The potential IAA production was approximately three to four times the actual at 24 and $48 \mathrm{~h}$, respectively, in culture (Fig. 2A). The auxin-responsive gene GH3.3, involved in auxin conjugation, was significantly upregulated by B. japonicum in A. thaliana roots within the first $24 \mathrm{~h}$ of cocultivation (Fig. 2B).

To further determine whether B. japonicum could influence internal plant auxin levels, transgenic $A$. thaliana plants expressing the synthetic DIRECT REPEAT 5 (DR5) auxin-responsive promoter fused to the $\beta$-glucuronidase $(G U S)$ reporter gene (DR5:GUS) were employed (Casimiro et al. 2001; Ulmasov et al. 1997; Zamioudis et al. 2013). At 4 dpi, GUS staining in control plants was detected in the PR tip, in LRP, and at the tips of emerged LR (Fig. 2C). In B. japonicum-inoculated seedlings, GUS staining was remarkably enhanced in the root tip and along 
the entire root, including LRP and LR (Fig. 2C). Because DR5 activity correlates with auxin content in roots, accumulation of the DR5 reporter indicated increased root auxin levels with $B$. japonicum treatment, likely due to enhanced environmental IAA produced by the bacteria surrounding the roots (Casimiro et al. 2001). The increase in auxin responsiveness in the presence of $B$. japonicum suggests microbial interference with plant auxin concentration and subsequent auxin-regulated gene expression.

\section{Inhibition of auxin efflux transport reduces}

\section{B. japonicum-induced LR development.}

Auxin movement in and out of cells is controlled by membrane diffusion and carrier-mediated transport (Gutknecht and Walter 1980; Kramer and Bennett 2006). Application of the auxin efflux inhibitor N-1-naphthylphthalamic acid (NPA)
$(1 \mu \mathrm{M})$ was used to investigate the role of auxin efflux transport in B. japonicum-induced root alteration. NPA has been shown to block basipetal auxin transport and arrest LR growth (Casimiro et al. 2001; Teale and Palme 2018). Our data substantiated previous findings, as demonstrated by a decrease in LR number in control plants grown on agar media containing $1 \mu \mathrm{M}$ NPA (Fig. $3 \mathrm{~A})$. The presence of NPA in the growth media also significantly reduced the number of LR in plants treated with $1 \mu \mathrm{M}$ NAA, B. japonicum culture filtrate, or B. japonicum cells at 4 and 8 dpi (Fig. 3A). NPA decreased B. japonicum-stimulated LR formation to the level of untreated control plants (Fig. 3A), suggesting that auxin efflux transport inhibited by NPA is required for B. japonicum-induced LR increases. The number of LR formed by the addition of NAA was higher than those formed after treatment with B. japonicum or its culture filtrate.
A

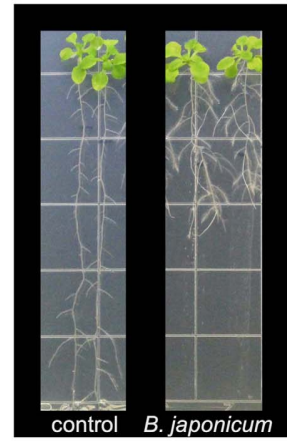

B

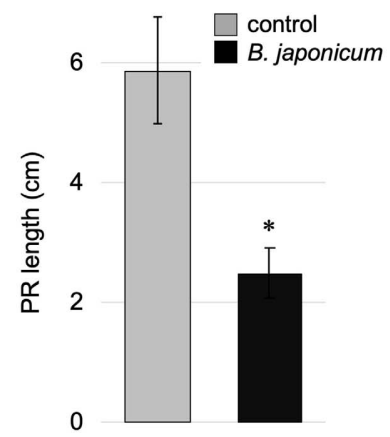

C

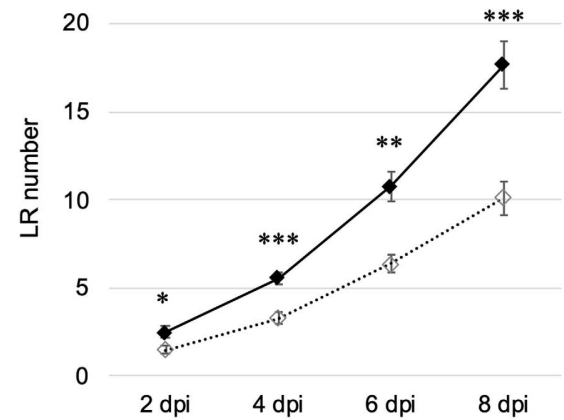

Fig. 1. Bradyrhizobium japonicum cocultivation induces primary root (PR) length reduction and increases lateral root (LR) number in Arabidopsis thaliana. A. thaliana Columbia (Col-0) seedlings were grown with either B. japonicum bacterial suspension or $10 \mathrm{mM} \mathrm{MgSO}_{4}$ (control). A, Representative photos of Col-0 root architecture 14 days postinoculation (dpi). B, Average PR length 6 dpi, gray $=$ control and black $=B$. japonicum, $P<0.05$. C, Col0 LR number was counted under microscopy every 2 dpi. Solid line $=B$. japonicum and dotted line $=$ control; error bars represent standard error for six biological replicates, $n>10$. Student's $t$ test, ${ }^{*},{ }^{* *}$, and ${ }^{* * *}$ indicate $P<0.05,0.01$, and 0.001 , respectively.

A

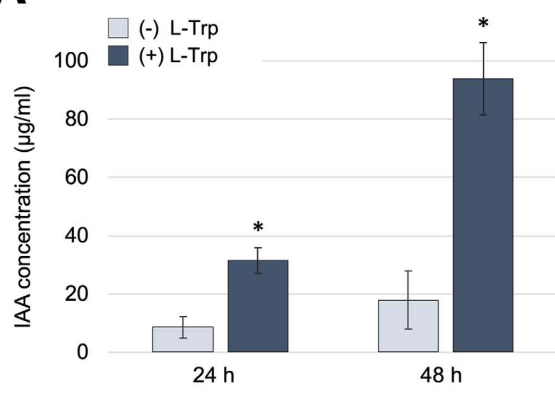

B

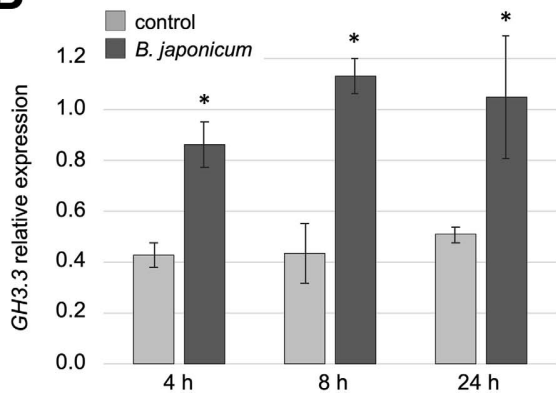

C

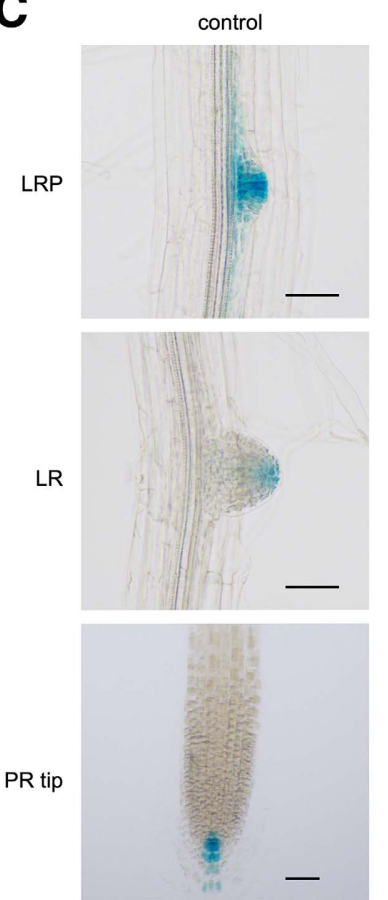

B. japonicum

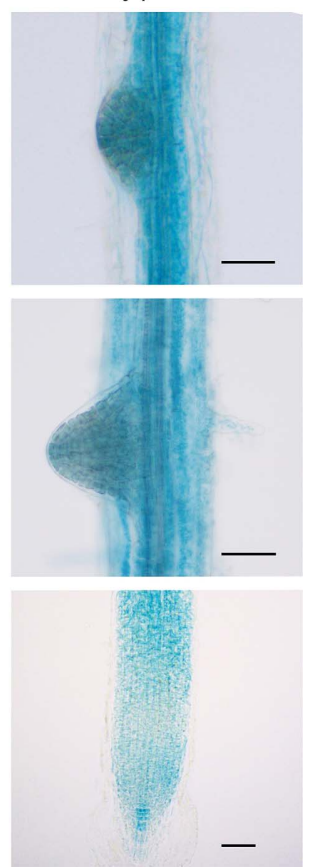

Fig. 2. Bradyrhizobium japonicum produces auxin in culture and enhances auxin responses in plants. A, Indole-3-acetic acid (IAA) concentration increased in the bacterial culture when L-tryptophan (L-Trp) was added, as measured by spectrophotometry. B, Reverse-transcription PCR measurement of GH3.3 expression relative to the ACTIN reference gene in roots of control and B. japonicum-inoculated plants at 4 , 8 , and $24 \mathrm{~h}$ postinoculation (hpi). Student's $t$ test determined significant differences at each time point, $P<0.05$. C, Images of stained DR5: $\beta$-glucuronidase roots 4 days postinoculation (dpi). $\mathrm{LRP}=$ lateral root primordia, $\mathrm{LR}=$ lateral root, and $\mathrm{PR}=$ primary root; bar $=50 \mu \mathrm{m}$. 
The greatest percent LR reduction by NPA was observed in control and NAA-treated plants, while the lowest was in plants treated with B. japonicum or its culture filtrate (Supplementary Fig. S3). Primary root length was reduced by NPA, B. japonicum, and culture filtrate and was arrested by the combination of B. japonicum plus NPA (Fig. 3B). Because NPA and DMSO did not hinder the growth of B. japonicum cells in culture (Supplementary Fig. S4), the compounds do not appear to disrupt bacterial function. In addition, B. japonicum displayed a lack of microbe sensitivity to the treatment compounds when grown on

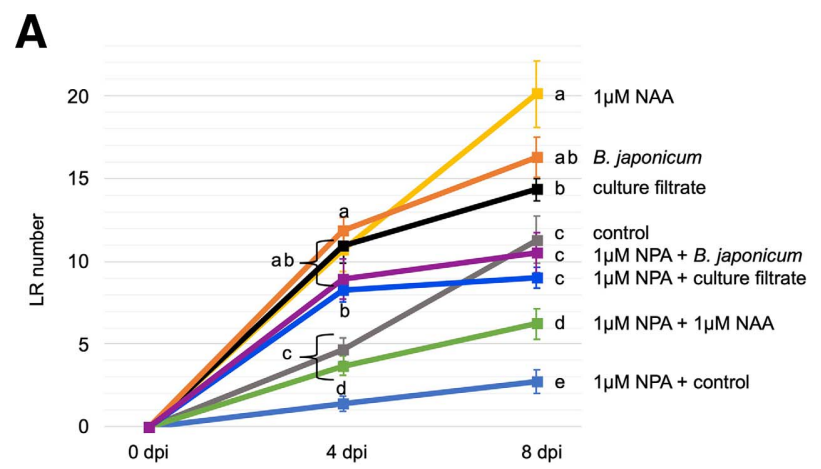

\section{B}
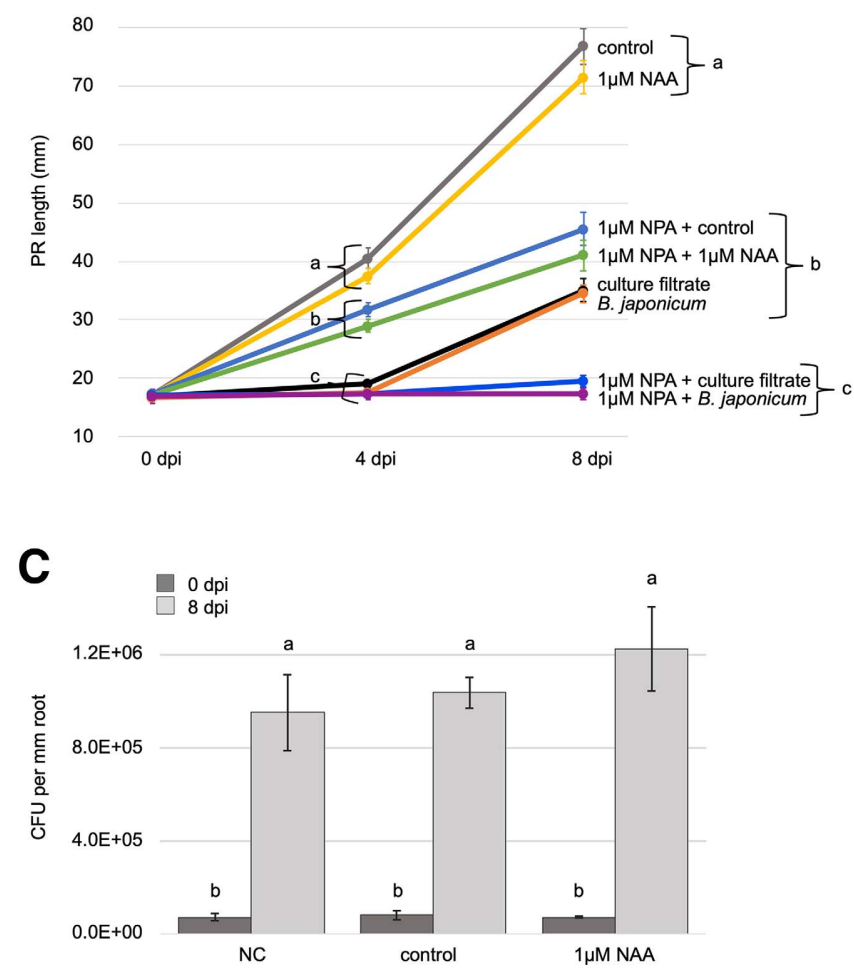

Fig. 3. Inhibition of auxin efflux transport affects Bradyrhizobium japonicum-stimulated lateral root (LR) growth and primary root (PR) length. Columbia (Col-0) 5-day-old plants were transferred to agar plates containing the auxin efflux inhibitor N-1-naphthylphthalamic acid (NPA; 1 $\mu \mathrm{M}$ ) in $0.1 \%$ dimethyl sulfoxide (DMSO), or solvent alone. These plants were treated with $10 \mu \mathrm{l}$ of either $1 \mu \mathrm{M}$ naphthalene-1-acetic acid (NAA), B. japonicum culture filtrate, B. japonicum, or their control, added to root tips. A, LR numbers were counted at 0,4 , and 8 days postinoculation (dpi). B, PR lengths were measured at 0,4 , and 8 dpi. C, B. japonicum $\mathrm{CFU}$ were recovered from roots treated with no compound (NC), $0.1 \%$ DMSO, or $1 \mu \mathrm{M}$ NAA at 0 and 8 dpi. Graphs are averages from two independent experiments; standard error bars, $n>10$. Data-appropriate tests (A and B, Welch's analysis of variance [ANOVA] and Games-Howell; $\mathrm{C}$, ANOVA and Tukey), $P<0.05$, were used to determine significant differences. For A and B, statistical analysis was performed separately for each time point. plates (Fig. 3C). No significant differences were seen between $B$. japonicum $\mathrm{CFU}$ recovered from roots treated with either no compound (NC), $0.1 \%$ DMSO, or $1 \mu \mathrm{M}$ NAA at 8 dpi (Fig. 3C).

\section{B. japonicum increases $P I N$ and $A B C B$ gene expression.}

Our results strongly suggested that auxin efflux carriers play a role in B. japonicum-induced root architecture alterations. Therefore, we investigated $B$. japonicum-stimulated gene expression modifications by performing RNA-sequencing (RNA-seq) analysis of Col-0 whole-root tissue. A general increase in auxin-related gene transcript levels was evident in the B. japonicum-inoculated roots (Supplementary Fig. S5), and more than 70 differentially regulated distinct auxin-related genes were identified at $14 \mathrm{dpi}$ (Table 1). In the RNA-seq data, significant increases in transcripts of auxin efflux transporters PIN2 (1.44 $\log _{2}$-fold-change [FC]), PIN7 (4.15 FC), and ABCB19 (1.22 FC) were observed under $B$. japonicum cocultivation (Table 1). PIN3 transcripts increased (mean read counts were nearly $41 \%$ higher than control) but the data were not statistically significant. $A B C B 4$ and PIN1 transcript levels did not show a clear change between inoculated and control roots. Other auxin-related genes upregulated by B. japonicum included ARF7 (6.60 FC), IAA14 (4.31 FC), PILS7 (4.15 FC), ICR1 (3.68 FC), GH3.6 (2.41 FC), and $A R F 5$ ( $2.27 \mathrm{FC})$, while among the downregulated genes were IAA28 (-1.08 FC), PILS3 (-1.10 FC), and BIG (-6.88 FC) (Table 1). Sequential activation of auxin response modules during LR development is a highly coordinated event (Lavenus et al. 2015). Our RNA-seq data are a snapshot of B. japonicum's influence over host transcriptional reprogramming in the root system (Table 1; Supplementary Fig. S5).

Quantitative real-time PCR (qRT-PCR) gene expression studies also illustrated transcriptional changes in auxin transporters after treatment with $B$. japonicum. We measured transcript levels of six major auxin efflux transporters in the roots of Col-0 plants at $12 \mathrm{~h}$ postinoculation (hpi). The 12-h time point was chosen to catch early transcriptional changes in response to $B$. japonicum cocultivation. PIN3, PIN7, and $A B C B 19$ were upregulated in $B$. japonicum-treated whole-root tissues (Fig. 4). $A B C B 4$ expression increased, but not significantly. There were no significant differences between inoculated and noninoculated root transcript levels of PIN1 or PIN2 in the qRT-PCR data (Fig. 4). qRT-PCR and RNA-seq analyses detected significant increases in PIN7 and $A B C B 19$ expression with $B$. japonicum. RNA-seq analysis detected an increase in PIN2 expression whereas PIN3 upregulation was found to be significantly higher only in the qRT-PCR experiments $(P<0.01)$ in inoculated roots. Differential observations between the two assays reflect gene expression fluctuations over time with $B$. japonicum cocultivation.

\section{Auxin efflux transport mutants display altered B. japonicum-induced LR growth.}

To further demonstrate putative roles for auxin efflux carriers in $B$. japonicum-induced root alterations, we investigated the effect of $B$. japonicum on LR formation in A. thaliana singlegene mutants with interrupted function in PIN2 (pin2 and Salk_122916C), PIN3 (pin3-3 and pin3-4), PIN7 (pin7 and Salk_048791C), $A B C B 4$ (abcb4-2 and pgp4-1), and $A B C B 19$ (abcb19-3 and atmdr1-101) (Fig. 5). Disruption of auxin efflux transport genes in A. thaliana mutants resulted in differential LR growth when cocultivated with B. japonicum (Fig. 5). Although higher in the pin2 alleles, the LR number per seedling in noninoculated pin3, pin7, abcb4, and $a b c b 19$ mutant plants was similar to Col-0 at 8 dpi (Fig. 5). In B. japonicum-inoculated plants, LR numbers increased in wild type, pin2, and $a b c b 4$ lines (Fig. 5). However, B. japonicum did not increase LR numbers in pin3, $\operatorname{pin} 7$, and $a b c b 19$ as it did in wild-type plants (Fig. 5). Without functional PIN3, PIN7, or $A B C B 19$ genes, the inoculated LR 
Table 1. RNA-sequencing differentially expressed auxin-related genes

\begin{tabular}{|c|c|c|c|}
\hline AGI & $\log _{2}$-fold change & Gene & Gene name and descriptive phrases ${ }^{a}$ \\
\hline AT5G05730.2 & 6.78 & $A S A 1^{\mathrm{b}}$ & $\begin{array}{l}\text { Anthranilate synthase } \alpha \text { subunit } 1 \text {; tryptophan synthesis, lateral root } \\
\quad \text { formation, response to bacterium }\end{array}$ \\
\hline AT5G20730.1 & 6.60 & ARF7 & Auxin response factor 7; auxin-regulated transcriptional activator \\
\hline AT1G28560.3 & 4.70 & $S R D 2^{\mathrm{b}}$ & $\begin{array}{l}\text { Shoot redifferentiation defective 2; organ morphogenesis, polar transport, } \\
\text { cellular response to auxin stimulus, lateral root formation, meristem } \\
\text { initiation }\end{array}$ \\
\hline AT4G02570.1 & 4.70 & AXR6 & Auxin-resistant 6; mediating responses to auxin \\
\hline AT1G14350.4 & 4.70 & $F L P$ & Four lips; auxin polar transport, regulation of lateral root development \\
\hline AT3G44310.2 & 4.59 & NIT1 & $\begin{array}{l}\text { Nitrilase 1; auxin biosynthetic process, indole-3-acetonitrile (IAN) to } \\
\text { indole-3-acetamide (IAM) conversion }\end{array}$ \\
\hline AT4G13260.1 & 4.34 & $Y U C 2$ & $\begin{array}{l}\text { Yucca 2; indole-3-pyruvic acid (IPA) to indole-3-acetic acid (IAA) } \\
\text { conversion, auxin biosynthetic process }\end{array}$ \\
\hline AT4G14550.2 & 4.31 & $S L R$ & $\begin{array}{l}\text { Solitary root, (aka IAA14); lateral root development, expressed in stele and } \\
\text { root tip epidermis }\end{array}$ \\
\hline AT5G65980.1 & 4.15 & PILS7 & Pin-likes 7; auxin efflux carrier \\
\hline AT3G23050.2 & 4.12 & $A X R 2^{\mathrm{b}}$ & Auxin-resistant 2, (aka IAA7); repressor of auxin-inducible gene expression \\
\hline AT5G62380.1 & 3.98 & NAC101 & NAC-domain protein 101 ; response to auxin \\
\hline AT2G46370.1 & 3.95 & $J A R 1^{\mathrm{b}}$ & $\begin{array}{l}\text { Jasmonate-resistant } 1 \text {; member of the GH3 family of proteins, cellular } \\
\text { response to auxin stimulus }\end{array}$ \\
\hline AT5G48070.1 & 3.72 & XTH2O & $\begin{array}{l}\text { Xyloglucan endotransglycosylase/hydrolase } 20 \text {; expressed in lateral root } \\
\text { primordia, cell growth, cellular response to auxin stimulus }\end{array}$ \\
\hline AT1G17140.2 & 3.68 & ICRI & Interactor of constitutively active ROP 1 ; regulation of auxin polar transport \\
\hline AT1G25220.2 & 3.55 & $A S B 1^{\mathrm{b}}$ & $\begin{array}{l}\text { Anthranilate synthase } \beta \text { subunit } 1 \text {, (aka WEI7); auxin biosynthetic process, } \\
\quad \text { lateral root formation, response to bacterium }\end{array}$ \\
\hline AT5G63160.3 & 3.52 & $B T 1$ & $B T B$ and $T A Z$ domain protein 1 ; response to auxin \\
\hline AT2G23260.1 & 3.38 & UGT84B1 & UDP-glucosyltransferase $84 \mathrm{~B} 1$; regulation of auxin metabolic process \\
\hline AT2G01940.3 & 3.25 & IDD15 & $\begin{array}{l}\text { Indeterminate(ID)-domain 15; regulation of auxin biosynthesis and } \\
\text { transport }\end{array}$ \\
\hline AT1G23080.3 & 2.89 & PIN7 & Pin-formed 7; auxin efflux, pattern specification during root development \\
\hline AT1G25250.3 & 2.85 & $I D D 16$ & $\begin{array}{l}\text { Indeterminate(ID)-domain 16; regulation of auxin biosynthesis and } \\
\text { transport }\end{array}$ \\
\hline AT2G22330.1 & 2.69 & CYP79B3 & $\begin{array}{l}\text { Cytochrome P450 family } 79 \text { subfamily B polypeptide 3; tryptophan } \\
\text { metabolism }\end{array}$ \\
\hline AT5G54490.1 & 2.46 & $P B P 1$ & Pinoid-binding protein 1 ; upregulated by auxin \\
\hline AT5G54510.1 & 2.41 & GH3.6 & $\begin{array}{l}\text { Gretchen Hagen 3.6; auxin homeostasis, auxin-activated signaling pathway, } \\
\text { response to auxin, unidimensional cell growth }\end{array}$ \\
\hline AT1G28130.1 & 2.39 & GH3.17 & Gretchen Hagen 3.17; auxin homeostasis, response to auxin \\
\hline AT1G19850.1 & 2.27 & ARF5 & Auxin response factor 5, (aka IAA24) \\
\hline AT1G75580.1 & 2.15 & SAUR51 & Small auxin upregulated RNA 51 ; response to auxin \\
\hline AT3G62100.1 & 2.15 & IAA30 & IAA inducible 30 ; response to auxin, root quiescent center \\
\hline AT4G39950.1 & 1.84 & CYP79B2 & $\begin{array}{l}\text { Cytochrome P450 family } 79 \text { subfamily B polypeptide } 2 \text {; tryptophan } \\
\text { metabolism, indoleacetic acid biosynthetic process, response to bacterium }\end{array}$ \\
\hline AT1G68130.1 & 1.70 & $I D D 14$ & $\begin{array}{l}\text { Indeterminate (ID)-domain 14; regulation of auxin biosynthesis and } \\
\text { transport }\end{array}$ \\
\hline AT4G31500.1 & 1.69 & SUR2 & $\begin{array}{l}\text { Superroot 2; adventitious root development, defense response to bacterium, } \\
\text { indoleacetic acid biosynthetic process, tryptophan biosynthetic process }\end{array}$ \\
\hline AT4G37390.1 & 1.67 & AUR3 & Auxin-regulated 3; regulation of auxin activity \\
\hline AT1G02335.1 & 1.67 & $P D G L P 2$ & $\begin{array}{l}\text { Plasmodesmal germin-like protein 2; primary root growth regulation by } \\
\text { controlling phloem-mediated allocation of resources between the primary } \\
\text { and lateral root meristems }\end{array}$ \\
\hline AT5G05730.1 & 1.55 & $A S A 1^{\mathrm{b}}$ & $\begin{array}{l}\text { Anthranilate synthase } \alpha \text { subunit } 1 ; \text { tryptophan synthesis, lateral root } \\
\quad \text { formation, response to bacterium }\end{array}$ \\
\hline AT1G12140.1 & 1.46 & DAO2 & $\begin{array}{l}\text { Dioxygenase for auxin oxidation 1; auxin homeostasis, expressed in root } \\
\text { caps }\end{array}$ \\
\hline AT2G22240.1 & 1.45 & $M I P S 2^{\mathrm{b}}$ & $\begin{array}{l}\text { Myo-inositol-1-phosphate synthase isoform 2; defense response to } \\
\text { bacterium, response to auxin }\end{array}$ \\
\hline AT5G57090.1 & 1.44 & PIN2 & $\begin{array}{l}\text { Pin-formed 2, (aka EIR1); auxin efflux, auxin polar transport, response to } \\
\text { auxin }\end{array}$ \\
\hline AT1G59750.2 & 1.39 & $A R F 1$ & $\begin{array}{l}\text { Auxin response factor } 1 \text {; mediator of auxin response gene expression, } \\
\text { negative regulation of transcription, regulation of transcription }\end{array}$ \\
\hline AT3G23050.1 & 1.36 & $A X R 2^{\mathrm{b}}$ & Auxin-resistant 2, (aka IAA7); repressor of auxin-inducible gene expression \\
\hline AT2G04160.1 & 1.35 & AIR3 & Auxin induced root cultures 3; lateral root morphogenesis, response to auxin \\
\hline AT2G21050.1 & 1.24 & LAX2 & Like auxin-resistant 2 ; auxin influx carrier \\
\hline AT4G14740.1 & 1.24 & FL3 & Forked-like 3; auxin-activated signaling pathway \\
\hline AT1G48690.1 & 1.23 & No name & Auxin-responsive GH3 family protein \\
\hline AT3G28860.1 & 1.22 & $A B C B 19$ & ATP-binding cassette B19; auxin transport \\
\hline AT2G37080.3 & 1.18 & $R I P 2$ & ROP interactive partner 2 ; response to auxin \\
\hline AT5G66700.1 & 1.16 & $H B 53$ & Homeobox 53; auxin-inducible, root development \\
\hline AT2G06850.1 & 1.14 & XTH4 & $\begin{array}{l}\text { Xyloglucan endotransglucosylase/hydrolase } 4 \text {; secondary cell wall } \\
\text { biogenesis, response to auxin }\end{array}$ \\
\hline
\end{tabular}

(Continued on next page)

\footnotetext{
${ }^{a}$ Minimal phrases representative of genes from The Arabidopsis Information Resource; aka = also known as.

${ }^{\mathrm{b}}$ Splice variants are differentially regulated.
} 
Table 1. (Continued from previous page)

\begin{tabular}{|c|c|c|c|}
\hline AGI & $\log _{2}$-fold change & Gene & Gene name and descriptive phrases ${ }^{a}$ \\
\hline AT1G56220.4 & 1.11 & No name & Dormancy/auxin associated family protein \\
\hline AT1G04240.1 & 1.08 & SHY2 & Short hypocotyl 2, (aka IAA3); regulates multiple auxin responses in roots \\
\hline AT1G04250.1 & 1.05 & $A X R 3$ & $\begin{array}{l}\text { Auxin-resistant 3, (aka IAA17); repressor of auxin-inducible gene } \\
\text { expression, auxin signaling }\end{array}$ \\
\hline AT1G09560.1 & 1.04 & $P D G L P 1$ & $\begin{array}{l}\text { Plasmodesmal germin-like protein 1; primary root growth regulation by } \\
\text { controlling phloem-mediated allocation of resources between the primary } \\
\text { and lateral root meristems }\end{array}$ \\
\hline AT2G20610.2 & 1.02 & SUR1 & $\begin{array}{l}\text { Superroot 1, (aka ALF1); auxin production, lateral roots, adventitious root } \\
\text { development, indoleacetic acid biosynthetic process, regulation of cell } \\
\text { growth by extracellular stimulus }\end{array}$ \\
\hline AT1G25220.1 & 1.01 & $A S B 1^{\mathrm{b}}$ & $\begin{array}{l}\text { Anthranilate synthase } \beta \text { subunit 1, (aka WEI7); auxin biosynthetic process, } \\
\text { lateral root formation, response to bacterium }\end{array}$ \\
\hline AT5G25620.1 & -1.01 & YUC6 & Yuсcа 6; auxin biosynthesis, response to oxidative stress \\
\hline AT1G51950.1 & -1.03 & IAA18 & IAA inducible 18 ; response to auxin \\
\hline AT1G22530.2 & -1.06 & PATL2 & Patellin 2; cellular response to auxin stimulus, auxin polar transport \\
\hline AT5G25890.1 & -1.08 & IAA28 & $\begin{array}{l}\text { IAA inducible 28; negative regulation of auxin responsive lateral root } \\
\text { formation, resistance to inhibition of root elongation by auxin }\end{array}$ \\
\hline AT3G44300.1 & -1.10 & NIT2 & Nitrilase 2 ; indoleacetic acid biosynthetic process, response to bacterium \\
\hline AT1G76520.1 & -1.10 & PILS3 & Pin-likes 3; auxin efflux carrier family protein \\
\hline AT4G28720.1 & -1.13 & CKRC2 & $\begin{array}{l}\text { Cytokinin induced root curling 2, (aka YUC8); auxin biosynthetic process } \\
\text { regulation }\end{array}$ \\
\hline AT1G77850.2 & -1.13 & ARF17 & $\begin{array}{l}\text { Auxin response factor 17; adventitious root development, auxin-activated } \\
\text { signaling pathway }\end{array}$ \\
\hline AT5G35735.1 & -1.14 & No name & Auxin-responsive family protein \\
\hline AT5G56750.2 & -1.22 & $N D L 1$ & $\begin{array}{l}N \text {-MYC downregulated-like } 1 ; \text { response to auxin, regulation of auxin polar } \\
\text { transport }\end{array}$ \\
\hline AT2G47460.1 & -1.23 & MYB12 & MYB domain protein 12 ; positive regulation of transcription, response to auxin \\
\hline AT5G17300.1 & -1.24 & $R V E 1$ & $\begin{array}{l}\text { Reveille } 1 \text {; auxin-activated signaling pathway, auxin biosynthetic process } \\
\text { regulation }\end{array}$ \\
\hline AT5G13370.1 & -1.27 & GH3.15 & Gretchen Hagen 3.15; conjugates glutamine to IBA, auxin homeostasis \\
\hline AT5G08640.1 & -1.63 & FLS1 & Flavonol synthase 1 ; response to auxin \\
\hline AT3G55120.1 & -1.94 & $\mathrm{CHI}$ & Chalcone flavanone isomerase; response to auxin \\
\hline AT1G04180.1 & -1.97 & YUC9 & Yисса 9; auxin biosynthetic process, response to ethylene \\
\hline AT2G42330.1 & -2.10 & $T M K 4$ & $\begin{array}{l}\text { Transmembrane kinase 4; auxin signaling, auxin biosynthetic process } \\
\text { regulation }\end{array}$ \\
\hline AT4G17980.1 & -2.97 & NAC071 & Nac domain containing protein 71 ; cellular response to auxin stimulus \\
\hline AT1G74650.3 & -3.84 & MYB31 & MYB domain protein 31 ; response to auxin \\
\hline AT2G46370.4 & -4.07 & $J A R 1^{\mathrm{b}}$ & $\begin{array}{l}\text { Jasmonate-resistant } 1 \text {; member of the GH3 family of proteins, cellular } \\
\text { response to auxin stimulus }\end{array}$ \\
\hline AT2G22240.3 & -4.08 & MIPS $2^{\mathrm{b}}$ & $\begin{array}{l}\text { Myo-inositol-1-phosphate synthase isoform 2; defense response to } \\
\text { bacterium, response to auxin }\end{array}$ \\
\hline AT3G02875.3 & -4.57 & ILRI & IAA-leucine-resistant 1 ; IAA metabolic processes \\
\hline AT1G28560.1 & -4.99 & $S R D 2^{\mathrm{b}}$ & $\begin{array}{l}\text { Shoot redifferentiation defective 2; organ morphogenesis, polar transport, } \\
\text { cellular response to auxin stimulus, lateral root formation, meristem } \\
\text { initiation }\end{array}$ \\
\hline AT3G02260.1 & -6.88 & TIR3 & $\begin{array}{l}\text { Transport inhibitor response 3, (aka } B I G) \text {; auxin polar transport, lateral } \\
\text { root formation, unidimensional cell growth }\end{array}$ \\
\hline AT5G14420.4 & -8.25 & $R G L G 2$ & Ring domain ligase 2 ; auxin metabolic process \\
\hline
\end{tabular}

numbers were similar to those of noninoculated pin3, pin7, $a b c b 4$, and $a b c b 19$ mutants and wild-type plants (Fig. 5). This indicated that PIN3, PIN7, and ABCB19 may have nonredundant roles in the $A$. thaliana-B. japonicum interaction and that functional auxin efflux transport through PIN3, PIN7, and $A B C B 19$ was required for $B$. japonicum-induced LR production. The 8-dpi LR numbers of noninoculated pin2 plants were not significantly different from control or inoculated wild-type, pin2, or $a b c b 4$ plants (Fig. 5). Significant differences were found between Col-0 inoculated and noninoculated plants using Welch's analysis of variance (ANOVA) (Fig. 5) and the Student's $t$ test $(P<0.0001)$. No significant differences were observed between the two independent alleles for each gene under control or inoculation treatments (Fig. 5). Interestingly, application of $1 \mu \mathrm{M}$ NAA did not show the same LR growth trends seen with B. japonicum cocultivation in pin3, pin7, or abcb19 (Supplementary Fig. S6).

\section{B. japonicum enhances LR initiation and emergence efficiency.}

To find out whether the B. japonicum-increased number of emerged LR was due to enhanced LRP (stages I to VII) formation or promotion of emergence of already formed LRP, we counted the number of LRP at different developmental stages and emerged LR in auxin efflux mutants at 4 dpi. LRP stages were determined according to Torres-Martínez et al. (2019). When these data were graphed as a percentage of the total (total $=$ all LRP + emerged LR), both the proportions of each stage and the general distribution trend remained largely the same between control and inoculated roots (Supplementary Fig. S7).

Summation of two independent experiments revealed that the number of LRP (stages I to VII) at 4 dpi was slightly lower in inoculated relative to control wild-type Col- 0 roots whereas the number of emerged LR was increased by B. japonicum (Table 2 ). In inoculated Col- 0 plants, the increase $(72.6 \%)$ of emerged LR surpassed the decrease $(5.7 \%)$ in LRP stages I to VII. If this represented solely an acceleration of LRP progression toward emergence, the decrease in LRP would have likely closely matched the increase in emerged LR. Because the number of LRP was nearly maintained while the number of emerged LR increased, B. japonicum appears to have stimulated LR initiation as well as LR emergence, suggesting an overall acceleration in the rate of LR and LRP growth throughout LRP morphogenesis. 
Emerged LR significantly increased in Col-0, pin2, and $a b c b 4$ with B. japonicum cocultivation but decreased in pin7 (Table 2), similar to our observations at $8 \mathrm{dpi}$ (Fig. 5). Following B. japonicum inoculation, wild-type plants had a higher increase in the number of emerged LR than the mutants $(\mathrm{Col}-0=72.6 \%$ compared with pin 2 $=17.8 \%, \operatorname{pin} 3=2.6 \%, \operatorname{pin} 7=-9.3 \%, a b c b 4=24.7 \%$, and $a b c b 19$ $=2.9 \%$ ) (Table 2). Apart from $a b c b 4$, there was a greater reduction in LRP in the tested mutants than in Col-0 following B. japonicum inoculation $(\mathrm{Col}-0=5.7 \%$ compared with pin $2=12.1 \%$, pin3 $=$ $12.6 \%$, $\operatorname{pin} 7=26.5 \%$, and $a b c b 19=28.5 \%$ ) (Table 2). The percentage differences observed between Col- 0 and the loss-of-function mutants were most robustly demonstrated in $\operatorname{pin} 3$, pin7, and $a b c b 19$. Because B. japonicum had little effect on the overall proportions and distribution of LRP stages I to VII (Supplementary Fig. S7) but the number of total LRP decreased more dramatically in the mutants than in Col-0 (Table 2), these data suggest that PIN3, PIN7, and $A B C B 19$ were integral to the acceleration of LR growth throughout the LRP developmental stages and emergence.

PR length was significantly lower in B. japonicum-treated than control plants in Col-0, pin3, pin7, and abcb19 (Table 2). However, PR length remained unchanged in pin2 and insignificantly lowered in abcb4 with B. japonicum inoculation (Table 2), suggesting involvement of PIN2 in B. japonicum-induced PR reduction. The tested auxin efflux facilitators, as single-gene mutants, demonstrated differential roles in B. japonicum-activated $P R$ and $L R$ alterations.

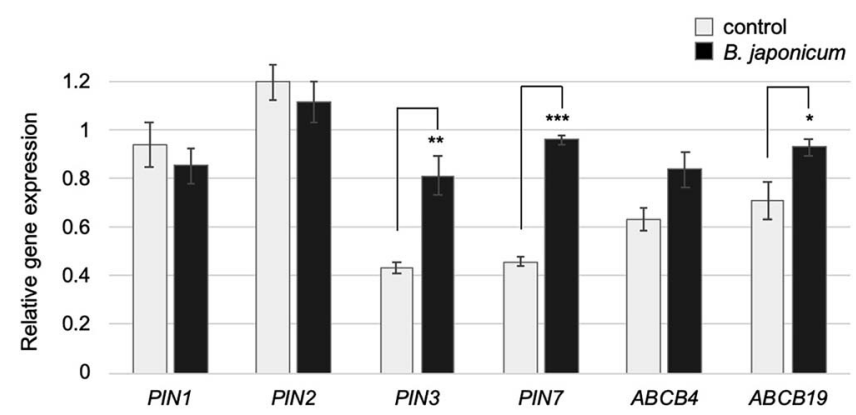

Fig. 4. Bradyrhizobium japonicum induced PIN3, PIN7, and ABCB19 gene expression in Arabidopsis thaliana root tissue at $12 \mathrm{~h}$ postinoculation. A. thaliana roots were treated with either B. japonicum or $10 \mathrm{mM}$ $\mathrm{MgSO}_{4}$ (control) for $12 \mathrm{~h}$. Quantitative reverse-transcription PCR expression data relative to the IPP2 reference gene showed significantly increased RNA transcripts in PIN7, PIN3, and ABCB19. Student's $t$ test, $*, * *$, and ${ }^{* * *}$ indicate $P<0.05,0.01$, and 0.001 , respectively.

\section{B. japonicum alters PIN3:green fluorescent protein (GFP), PIN7:GFP, and $A B C B 19: G F P$ expression localization.}

Confocal microscopy of green fluorescent protein (GFP) reporter line fluorescence was investigated after $B$. japonicum was found to increase PIN3, PIN7, and $A B C B 19$ transcript abundance in wholeroot Col-0 tissue, and LR and LRP data with pin3, pin7, and abcb19 mutants indicated roles for the genes in B. japonicum-stimulated root alterations. Imaging of three reporter lines demonstrated altered expression localization with B. japonicum cocultivation at 12 hpi in root tips (Fig. 6). Differential expression localization between control and inoculated plants was seen in the elongation zone of PIN3:GFP and PIN7:GFP and the meristematic zone of $A B C B 19: G F P$ (Fig. 6). Unlike control plants, fluorescent signals of inoculated PIN3:GFP and PIN7:GFP were minimal in the elongation zone (Fig. 6; Supplementary Fig. S8). Under control conditions, $A B C B 19: G F P$ is predominantly expressed in the central core of the differentiation zone and broadly expressed in the root apex and meristematic zone (Supplementary Fig. S9A and B) (Wu et al. 2007). When cocultivated with B. japonicum for $12 \mathrm{~h}$, $A B C B$ 19:GFP fluorescence nearly disappeared in the meristematic zone where it was confined to the columella and lateral root cap cells (Fig. 6). $A B C B 19: G F P$ fluorescence in the root central cylinder was visible and the B. japonicum-induced ABCB19:GFP fluorescence pattern was maintained at 24 hpi (Supplementary Fig. S9) (Sukumar et al. 2013b; Wu et al. 2007). A schematic diagram of $B$. japonicum-stimulated ABCB19:GFP, PIN3:GFP, and PIN7:GFP expression distribution, based on our confocal microscopy imaging and gene expression data, is illustrated in Figure 7. The diagram also shows previously reported PIN2, PIN3, PIN7, ABCB4, and $A B C B 19$ root tissue location and associated auxin flux directionality under control conditions (Fig. 7) (Geisler et al. 2017; Laskowski and ten Tusscher 2017).

Note that B. japonicum-stimulated PR reduction results in a significantly shorter elongation zone, as measured between the transition zone and the first apical root hair, compared with control roots (Supplementary Fig. S8) (Barrada et al. 2015; Di Mambro et al. 2017). No significant difference was observed in lengths between the quiescent center and the transition zone between inoculated and noninoculated plants (Supplementary Fig. S8).

\section{DISCUSSION}

Traits observed in roots inoculated with the B. japonicum strain IRAT FA3 phenocopy the exogenous auxin application increase and decrease to plant LR number and PR length, respectively. Not all strains of $B$. japonicum produce IAA and,

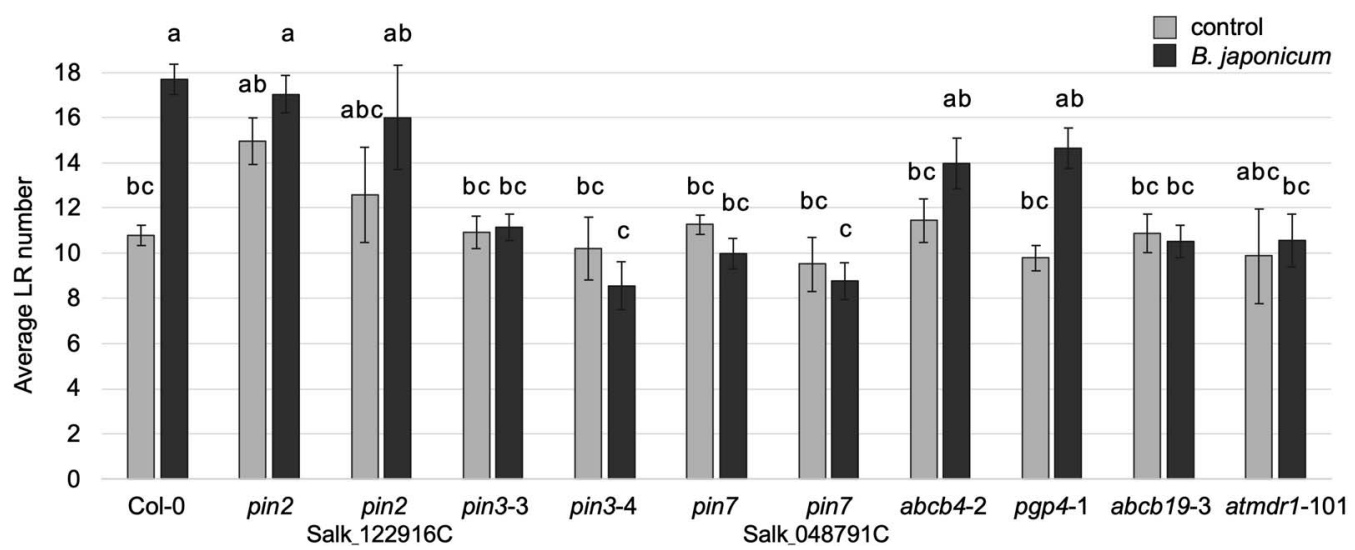

Fig. 5. Mutations in auxin efflux transport genes alter Bradyrhizobium japonicum-induced lateral root (LR) growth. Two independent mutant alleles were used for each gene (PIN2 [pin2 and Salk_122916C], PIN3 [pin3-3 and pin3-4], PIN7 [pin7 and Salk_048791C], ABCB4 [abcb4-2 and pgp4-1], and $A B C B 19$ [abcb19-3 and atmdr1-101]). The LR number per seedling was averaged at 8 days postinoculation (dpi) for at least two independent experiments. Different letters indicate statistical differences between treatments or lines analyzed by Welch's analysis of variance, Games-Howell $(P<0.05)$; standard error bars; $n>10$. 
arguably, one of the distinguishing factors between $B$. japonicum and the later-named species $B$. elkanii (previously $B$. japonicum) has been IAA production in culture (Minamisawa and Fukai 1991; Minamisawa et al. 1996). In B. japonicum E109, a widely used soybean inoculation strain, genome analysis revealed tryptamine pathway genes, IAA did not accumulate in culture, and auxin was degraded by this strain in the presence of added IAA, IBA, and NAA (Torres et al. 2018). Unlike E109, the B. japonicum IRAT FA3 strain used in this study produces IAA in culture and, with the IAA precursor L-tryptophan provided, IAA production increased (Dobbelaere et al. 1999). Our B. japonicum strain enhanced auxin responses in the plant root, as shown by intensified DR5-reporter staining and increased expression of $G H 3.3$, a gene that helps plants cope with excess auxin by synthesizing IAA-amino acid conjugates (Casimiro et al. 2001; Ulmasov et al. 1997; Zamioudis et al. 2013).

RNA-seq analysis revealed transcriptional changes in response to $B$. japonicum cocultivation in more than 70 differentially regulated auxin-related genes, several of which have previously demonstrated roles in either LR formation, PR length regulation, or auxin transport. For example, upregulation of $A R F 7, A R F 5$, and IAA14 suggests activation of LRP initiation, LRP cell fate specification, and LRP development (Dubrovsky et al. 2008; Lavenus et al. 2015; Torres-Martínez et al. 2019). Increased $G H 3.6$ expression may be related to feedback mechanisms that regulate auxin homeostasis during LRP initiation (Vanneste et al. 2005). An increase in ICRI, involved in the recruitment of PINs to polar plasma membrane domains, implies further regulation of auxin polar transport (Hazak et al. 2010). Differential regulation of PIN-LIKE genes PILS7 and PILS3 is indicative of intracellular auxin homeostasis management (Barbez et al. 2012). Downregulation of both $I A A 28$, a repressor of LR initiation, and $B I G$, with roles in auxin-mediated PIN cycling to increase PIN proteins at the plasma membrane and PR elongation, may promote progression of B. japonicum-mediated LR number increases and PR length reduction, respectively (Guo et al. 2013; Paciorek et al. 2005; Rogg et al. 2001; Zhang et al. 2019). ABCB4 and PIN1 transcript levels did not change with inoculation, suggesting a lack of involvement of these genes at this point in the $B$. japonicum-plant interaction. Chen and coworkers (2015) proposed a mechanism of regulation of transcriptional auxin sensitivity in which a PIN3 pathway, together with $A R F 7$ and $F L P$, may maintain locally enhanced auxin flux during LR growth. Given that the PIN3, ARF7, and $F L P$ genes were upregulated by $B$. japonicum, the proposed circuitry in Chen and coworkers (2015), if amplified by B. japonicum in wild-type plants, would be severed in the pin3 mutant, preventing a B. japonicum-stimulated LR number increase.
Treatment of inoculated plants with the auxin efflux inhibitor NPA significantly reduced the number of LR, pointing to the major role of polar auxin transport in B. japonicum-induced LR formation. NPA did not prevent $B$. japonicum cells or culture filtrate from inducing nearly the same number of LR as control plants without NPA, indicating that B. japonicum may rely, at least partially, on mechanisms other than those disrupted by NPA to increase LR development. The lack of significant differences in the number of LR formed by plants treated with the culture filtrate or B. japonicum cells, with or without NPA, demonstrated the importance of compounds produced by $B$. japonicum rather than the presence of the bacterial cells in stimulating LR growth. Auxin, produced by $B$. japonicum, may contribute to rescuing the NPA LR phenotype (Casimiro et al. 2001). NPA has been shown to have a greater effect on NAA than on IAA, which correlates with NPA's relatively lower effect on B. japonicum- and culture filtrate-stimulated LR production in our assay (Delbarre et al. 1996). Although the exact mechanism is still debated, there is evidence for NPA sensitivity, direct or indirect activity, or binding affinity among members of both the PIN and ABCB families (Abas et al. 2021; Blakeslee et al. 2007; Noh et al. 2001; RojasPierce et al. 2007; Teale and Palme 2018). Auxin efflux inhibition causes LRP defects similar to those observed in pin1pin3pin4 mutants, indicating that PIN-dependent auxin efflux is necessary for LRP development (Benková et al. 2003). Benková et al. (2003) also observed that mutations of PIN genes interfered with auxin gradients in LRP and with LRP development, indicating that LRP growth was dependent on PIN-regulated auxin gradients. $B$. japonicum-induced LR increases may largely be due to its auxin production and NPA may have reduced $B$. japonicuminduced LR growth by inhibiting auxin efflux transporters. Therefore, we investigated auxin transport gene cooperation in controlling the root growth responses to $B$. japonicum.

B. japonicum-treated auxin efflux transport mutants showed differential LR phenotypes compared with control plants. Three of the single mutant lines tested (pin3, pin7, and abcb19) had LR numbers similar to those of the wild-type Col-0 seedlings when noninoculated but significantly fewer LR than Col-0 when cocultivated with $B$. japonicum. Single pin mutants have been shown to have altered expression of the remaining functional PIN proteins that masks the defect of the mutation, demonstrating a somewhat compensatory expression in pin mutants under control conditions (Benková et al. 2003; Blilou et al. 2005). Such auxin transport system redundancy may account for the lack of differentiation in LR numbers between noninoculated individual mutants and wild-type plants, as well as the LR number increases seen in pin3 and pin7 with NAA application in our study (Benková et al. 2003). However, that functional redundancy was unable to prevent an absence

Table 2. Lateral root (LR) and LR primordia (LRP) count and average primary root (PR) percent reduction summary ${ }^{\mathrm{a}}$

\begin{tabular}{llcccc}
\hline Line & \multicolumn{1}{c}{ Treatment } & Sums & Emerged & Total & PR reduction \pm SE $(\%)$ \\
\hline Columbia (Col-0) & Control & 351 & 73 & 424 & - \\
& Bradyrhizobium japonicum & 331 & 126 & 457 & $10.3 \pm 1.6$ \\
pin2 & Control & 306 & 101 & 407 & - \\
& B. japonicum & 269 & 119 & 388 & $0.0 \pm 2.4$ \\
pin3 & Control & 231 & 76 & 309 & - \\
& B. japonicum & 202 & 78 & 280 & $13.3 \pm 3.7$ \\
pin7 & Control & 268 & 75 & 343 & - \\
& B. japonicum & 197 & 68 & 265 & - \\
abcb4 & Control & 238 & 77 & 315 & $3.7 \pm 3.8$ \\
& B. japonicum & 239 & 96 & 335 & - \\
& Control & 375 & 70 & 445 & $13.3 \pm 3.8$ \\
\hline
\end{tabular}

${ }^{a}$ Data from two independent experiments of seedlings treated with either $10 \mathrm{mM} \mathrm{MgSO}$ (control) or B. japonicum for 4 days were combined. LR count data are presented as the sums of LRP stages I to VII (Sums), emerged LR (Emerged), or both (Total). PR length percent reductions are averages; $\mathrm{SE}=$ standard error. Student's $t$ tests comparing each line's inoculated and noninoculated PR lengths gave the following $P$ values: Col-0 $(P=7.62 \mathrm{E}-04)$, $\operatorname{pin} 2(P=1.00), \operatorname{pin} 3(P=8.52 \mathrm{E}-04), \operatorname{pin} 7(P=4.79 \mathrm{E}-07), a b c b 4(P=0.45)$, and $a b c b 19(P=2.69 \mathrm{E}-02)$. 
of B. japonicum-stimulated LR growth in single pin3, pin7, or abcb19 mutants, suggesting independent roles for PIN3, PIN7, and ABCB19 during the plant-B. japonicum interaction.

Although the synthetic auxin NAA serves as a positive control in activating Col-0 LR growth, it is not likely to fully capture the nuances, feedback, or reactivity between living organisms over time (Spaepen et al. 2007). NAA did not reduce Col-0 PR length, nor did it lower LR numbers in pin3 or pin7 as B. japonicum did. These differences could reflect (i) the mode of treatment (i.e., a single, topical $1-\mu \mathrm{M}$ NAA application differs from inoculum containing thousands of microbes that grow over time), (ii) specific auxin compound differences between those produced by bacteria and synthetic NAA, (iii) NAA and IAA diffusive influx capacity and efflux transporter affinity differences, or (iv) unidentified compounds produced by B. japonicum (Asari et al. 2017; Blakeslee et al. 2007; Boiero et al. 2007; Delbarre et al. 1996). Although this study identifies IAA as a major factor produced by B. japonicum, it is likely that additional compounds also have roles in A. thaliana growth promotion, the analyses of which deserve future study (Asari et al. 2017; Boiero et al. 2007; Delbarre et al. 1996). A variety of priming signals are capable of specifying cells to become founder cells and prebranch sites that will form LR, and such cues may be produced or stimulated by $B$. japonicum (Laskowski and ten Tusscher 2017). Likewise, an increase in exogenous IAA produced by the bacteria may promote LRP initiation, speed LR development or emergence, and shorten PR.

Previous studies have shown that treatment of plants with auxins increased expression of PIN3 and PIN7, which corroborates our gene expression analysis of $A$. thaliana cocultivated with the IAA-producing strain of B. japonicum (Lewis et al. 2011; Vieten et al. 2005). Despite the close evolutionary relationship and pathway-level coexpression between PIN3 and PIN7, plus their known roles in root development, redundant cooperation between these two genes in B. japonicum-inoculated plants was not obvious (Chen et al. 2015; Friml et al. 2002; Paponov et al. 2005; Ruiz Rosquete et al. 2018; Zhou and Luo
2018). PIN3, as a mediator of auxin flux between the pericycle and endodermis, is a major player in LR initiation following founder cell specification and in LR emergence facilitation (Marhavý et al. 2013; Péret et al. 2013). PIN3:GFP and PIN7:GFP reporter lines displayed a change in root tip expression localization of PIN3 and PIN7, respectively, with $B$. japonicum cocultivation. Fluorescent signals in both lines were minimal in the elongation zone (i.e., basipetal of the auxin minimum of the transition zone and acropetal to the first apical root hair) in inoculated compared with control roots (Barrada et al. 2015; Di Mambro et al. 2017). The elongation zone is significantly shorter in B. japonicum cocultivated roots at 12 hpi. To promote cell expansion, auxin levels are lower in the elongation zone; however, increases in auxin can rapidly inhibit cell elongation (Motte et al. 2019). Blilou et al. (2005) demonstrated that PIN-mediated auxin distribution controls cellular elongation and found the elongation zone to be reduced in the pin3pin4pin 7 triple mutant. Although inoculated pin3 and pin 7 did not demonstrate a PR length phenotype that was different from that of wild-type plants, altered GFP expression localization suggests a putative role for PIN3 and PIN7 related to auxin accumulation in the elongation zone with $B$. japonicum cocultivation.

B. japonicum-stimulated PR reduction may be due to microbially produced exogenous auxin levels, because IAA has been shown to reduce elongation zone size (Rahman et al. 2007). Nevertheless, differential regulation of PIN proteins by root architecture-altering soil bacteria has been recognized; for example, Achromobacter sp. 5B1 repressed expression of PIN7 in the root tip while increasing PIN3 expression in columella cells (Jiménez-Vázquez et al. 2020; Sukumar et al. 2013a). However, several PGPR studies have identified non-PIN plant interaction points. In plants treated with another PGPR (Bacillus megaterium), reduction in A. thaliana PR length was a result of decreased cell proliferation and cellular elongation in the root meristem (López-Bucio et al. 2007). In a study with a Pseudomonas sp. named WCS417, the PGPR promoted root cell division yet decreased the PR length by reducing cell

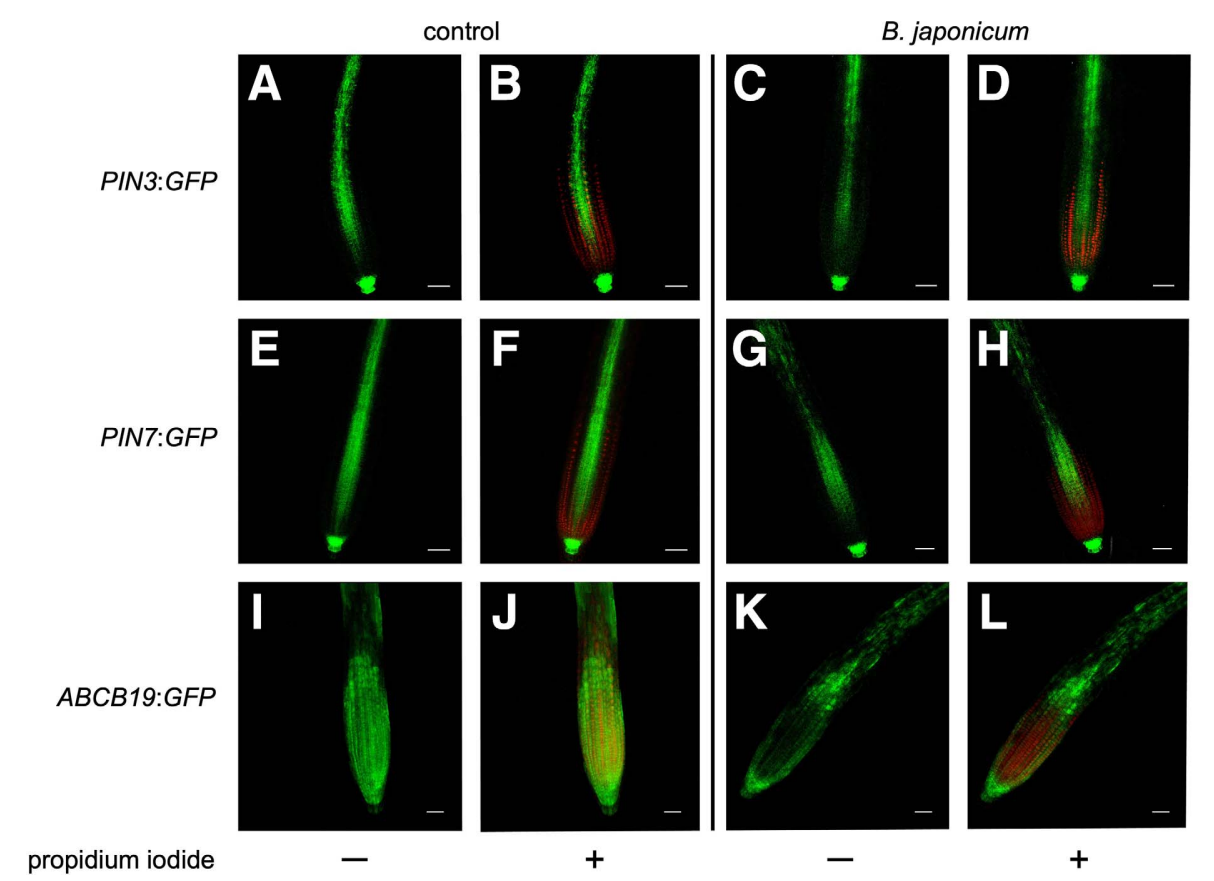

Fig. 6. Green fluorescent protein (GFP) expression localization changes in response to Bradyrhizobium japonicum. A to D, PIN3:GFP; E to H, PIN7:GFP; and I to L, ABCB19:GFP seedlings were grown for $12 \mathrm{~h}$ with either B. japonicum bacterial suspension or $10 \mathrm{mM} \mathrm{MgSO}_{4}$ (control) and imaged with confocal microscopy. GFP is shown in green and propidium iodide was used as a counterstain (red). Images are representative of three independent experiments. Scale bars $=50 \mu \mathrm{m}$. 
elongation in the elongation and differentiation zones (Zamioudis et al. 2013).

In our study, $a b c b 19$ had a similar number of LR as Col-0 under control conditions (Wu et al. 2007) but, unlike Col-0, the LR number did not increase in $a b c b 19$ with $B$. japonicum cocultivation. Thus, $A B C B 19$ appears to be required for $B$. japonicum-induced LR formation. To our knowledge, this is one of the first reports of $A B C B 19$ involvement in LR formation in a plant-PGPR interaction. It has been shown that ABCB19 is important for acropetal auxin transport and LR elongation and that ABCB19 stabilizes PIN PM localization, an interaction that enhances the rate of auxin transport, all of which could possibly be involved in B. japonicum-stimulated LR growth (Titapiwatanakun et al. 2009; Wu et al. 2007). A putative B. japonicumactivated ABCB19 pathway in the abcb19 mutant would lack

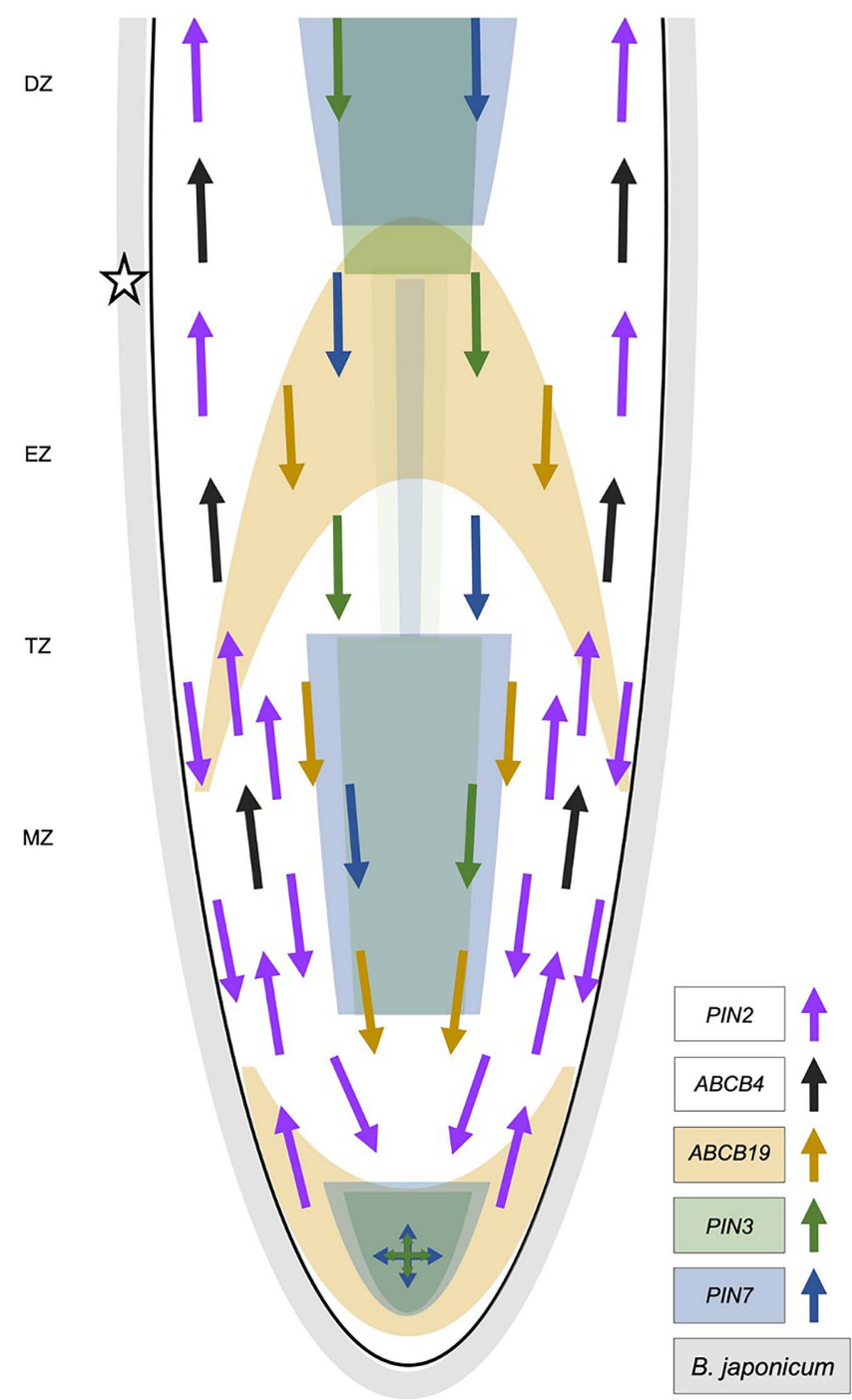

Fig. 7. Root tip auxin efflux system schematic diagram. Arrows indicate previously identified efflux transporter locations and auxin flux directionality of PIN2 (purple), PIN3 (green), PIN7 (blue), ABCB4 (black), and ABCB19 (tan) under control conditions (Geisler et al. 2017; Jozef et al. 2017; Laskowski and ten Tusscher 2017). Shading represents Bradyrhizobium japonicum-influenced localization of PIN3 (green), PIN7 (blue), and $A B C B 19$ (tan) gene expression based on reporter line confocal imaging at 12 hpi with $B$. japonicum. The bacteria are shown surrounding the root in gray; the star $(\star)$ indicates the location of the most apical root hair when cocultivated with B. japonicum at $12 \mathrm{hpi}$. DZ = differentiation zone, $\mathrm{EZ}=$ elongation zone, $\mathrm{TZ}=$ transition zone, and $\mathrm{MZ}=$ meristematic zone. the PIN PM stabilization; hence, the levels and rates of auxin transport needed to enhance the LR number would be absent.

Confocal microscopy of $A B C B 19: G F P$ roots with and without $B$. japonicum cocultivation revealed a change in the location of $A B C B 19$ promoter activity at 12 and $24 \mathrm{hpi}$. In the meristematic zone, fluorescence changed from diffuse distribution to more defined expression limited to the columella and lateral root cap in inoculated plants. Using a translational fusion reporter line, $\mathrm{Wu}$ et al. (2007) found an increase in ABCB19 protein when treated with IAA for $5 \mathrm{~h}$ in the location of the PR tip where our $A B C B 19$ promoter expression dissipated with $B$. japonicum at $12 \mathrm{hpi}$. Differential gene and protein expression localizations are not necessarily contradictory (Wu et al. 2007). Plus, the timing (7-h difference), growth conditions, and other factors at work during the plant-microbe interaction could contribute to the observed differences between our work and that of Wu et al. (2007). Both polar and nonpolar ABCB19 root cell localizations have been described (Blakeslee et al. 2007; Teale and Palme 2018; Titapiwatanakun et al. 2009; Wu et al. 2007). Both types of transport could be involved in the interaction with $B$. japonicum, such that differential $A B C B 19$ expression in the meristematic zone may be an indication of redirected auxin accumulation in regions where it is needed to increase LR formation. In addition, because ABCB proteins can affect mechanisms involved in PIN protein subcellular localization, B. japonicum-stimulated redirection of $A B C B 19$ expression may have downstream effects on other auxin transporters (Noh et al. 2003). Just as mdr4/abcb4's amplified auxin asymmetry was proposed as an explanation for that mutant's hypertropism (Lewis et al. 2007), redistribution of $A B C B 19$ expression by $B$. japonicum may account for some of the microbially induced root phenotypes. The $B$. japonicum-stimulated change in $A B C B 19-G F P$ root tip localization should not be confused with $A B C B 19$ expression levels throughout the entire root. The $A B C B 19$ transcript abundance increase with $B$. japonicum was observed in RNA extracted from whole-root tissues.

Although changes were observed in root tip localization, $A B C B 19$, PIN3, and PIN7 expression increased in whole-root tissue according to our RNA-seq and qRT-PCR data. Genes expressed in distinct root tissues, such as LRP, may have been diluted by the use of entire roots for qRT-PCR and RNA-seq analyses. Nevertheless, PIN2, PIN3, PIN7, and ABCB19 were upregulated by $B$. japonicum, an indication of roles for these genes in the plant-microbe interaction. The inability of B. japonicum to stimulate increased LR numbers in pin3, pin7, and $a b c b 19$ or $\mathrm{PR}$ reduction in pin2 is evidence of their respective involvement in B. japonicum-stimulated root alterations.

PIN2 does not appear to be required for B. japonicum-stimulated LR growth. According to Blilou et al. (2005), although PIN2 is crucial for basipetal auxin transport as well as regulation of cell division, this is only evident in pinlpin2 double mutants and in other multimutants containing pin2, because ectopic expression of other PIN proteins masks the defects. Such functional redundancy between PIN proteins may be the reason why we did not see significant changes in the LR numbers between pin 2 and Col-0 after inoculation with $B$. japonicum. On the other hand, pin2 significantly differed from Col-0 with regard to the B. japonicum-stimulated PR reduction phenotype. A role for PIN2 in PR length determination was also seen in Vieten et al. (2005), in which pin2 PR length was the same as pin1 and similar to WT but lower in pin1pin2. Pin2 and wild-type PR length decreased while LR number increased in response to the PGPR Bacillus megaterium in a study in which the pin 2 mutant had fewer LR than wild-type plants under control conditions (López-Bucio et al. 2007). B. megaterium inhibited PR growth by limiting cell proliferation and elongation (López-Bucio et al. 2007). In a separate study also using a Bacillus sp. (LZR216), inoculation reduced meristem length and cell division but 
promoted cell elongation in wild-type plants, yet pin2 PR length was unaffected by LZR216 (J. Wang et al. 2015). In our assay, the pin2 LR number was consistently higher than (but not significantly different from) Col-0 in noninoculated plants and increased to a similar level as Col-0 with Bradyrhizobium japonicum. Although mutant pin 2 PR length and LR number relative to the wild type can vary (depending on the allele, research conditions, and so on), multiple studies have associated loss of PIN2 function with differentially modulated root system architecture (Blilou et al. 2005; Laskowski et al. 2008; Li et al. 2015; López-Bucio et al. 2007; Qu et al. 2017).

Both PIN2 and $A B C B 4$ are involved in basipetal auxin flow, with the abcb4 mutant, (also known as pgp4 or $m d r 4$ ), having $50 \%$ of normal basipetal transport (Lewis et al. 2007; Müller et al. 1998). The pgp4-1 (SALK_063720) mutant was described as having shorter PR and fewer LR than wild-type plants, and PGP4 and $A B C B 4$ expression increased in response to IAA at $12 \mathrm{hpi}$ in previous work (Terasaka et al. 2005). Pgp4-1 did not show fewer LR under our assay's control or cocultivation conditions. Our qRT-PCR data show an insignificant $A B C B 4$ expression increase at 12 hpi with $B$. japonicum cocultivation that is far lower than that of the findings of Terasaka and coworkers (2005) in response to IAA. The auxin concentration applied in the Terasaka and coworkers (2005) qRT-PCR study was likely much higher than that produced by $B$. japonicum, especially at only $12 \mathrm{hpi}$. The $a b c b 4-2$ allele did not have a short PR under control conditions but it clearly demonstrated a lack of PR reduction in response to $B$. japonicum, a major difference from wild-type Col-0 plants, insinuating a role for $A B C B 4$ in PR growth related to $B$. japonicum influence, despite no increase in $A B C B 4$ gene expression in our study (Wu et al. 2007). ABCB4's functional plasticity as an efflux carrier under high IAA and an influx transporter at low IAA concentration could be used by B. japonicum at time points other than those recorded in this study (Kubeš et al. 2012).

Various species of PGPR have been shown to stimulate root growth and influence auxin signaling pathways (Grunewald et al. 2009; Jiménez-Vázquez et al. 2020; López-Bucio et al. 2007; Spaepen et al. 2014). Here, we showed that B. japonicum, an IAAproducing strain, activates auxin response, signaling, and transport genes; utilizes PIN2 and possibly $A B C B 4$ to reduce PR length; and requires PIN3, PIN7, and $A B C B 19$ to accelerate LRP development and LR emergence in $A$. thaliana roots. Our results provide insight into the auxin pathway points involved in B. japonicum-stimulated alteration of root morphology and a greater understanding of a mutualistic Bradyrhizobium microbe-plant interaction.

\section{MATERIALS AND METHODS}

\section{Plant material and growth conditions.}

All plants used in this study were in the A. thaliana Columbia (Col-0) background. Seeds were kindly provided by Gloria Muday (DR5:GUS, eirl-1 [aka pin2], pin3-3, pin7, abcb19-3, and ABCB19:GFP), Marta Laskowski (PIN3:GFP and PIN7:GFP). and Edgar Spaulding (abcb4-2) (Laskowski et al. 2008; Sukumar et al. 2013b; Wu et al. 2007). Col-0, pin2Salk_122916C, pin3-4 (CS9363), pin7-Salk_048791C, pgp4-1 (Salk_063720C), and atmdr1-101 (Salk_033455C) seeds were obtained from the Arabidopsis Biological Resource Center (The Ohio State University). Plants were grown vertically under light at 120 to $150 \mu \mathrm{mol} \mathrm{m} \mathrm{m}^{-2} \mathrm{~s}^{-1}$ and $22^{\circ} \mathrm{C}$ with a day and night cycle of 12 and $12 \mathrm{~h}$. Seeds were surface sterilized $(3 \mathrm{~min}$ in $10 \%$ [vol/vol] $\mathrm{NaClO}$ and $0.05 \%$ Tween solution, $1 \mathrm{~min}$ in $70 \%$ $\mathrm{EtOH}$, and four sterile water rinses) and cold treated at $4^{\circ} \mathrm{C}$ for 2 days before being sown onto a germination medium (1\% [wt/ vol] agar [Fisher Scientific], half-strength Murashige and Skoog [1/2 MS] supplemented with $0.01 \%$ myo-inositol, $0.5 \%$ sucrose, and $0.05 \%$ morpholineethanesulfonic acid, $\mathrm{pH} 5.7$ ). After 4 to 6 days, uniform seedlings were transferred to a treatment medium (1\% agar and 1/2 MS, $\mathrm{pH}$ 5.7), with eight seedlings per square Petri dish, for each treatment period.

\section{Bacterial cultivation and inoculation treatments.}

B. japonicum strain IRAT FA3 was originally isolated from Cameroon, Africa, and was characterized at the Institut de Recherches Agronomiques Tropicales (IRAT) in Montpelier, France, as strain number 3 (FA3) (Gachomo et al. 2014). B. japonicum was grown in half-LB $(1 / 2 \mathrm{LB})$ liquid medium at $28^{\circ} \mathrm{C}$ with shaking at $100 \mathrm{rpm}$ for 12 to $18 \mathrm{~h}$ from a previously grown stock. B. diazoefficiens (previously B. japonicum) USDA 110 LI (kindly provided by Joel Sachs) was grown in yeast-mannitol (YM) liquid medium at $29^{\circ} \mathrm{C}$ with shaking at $100 \mathrm{rpm}$ for 5 days. Bacteria cells were then collected by room-temperature centrifugation at $1,500 \times g$ for $15 \mathrm{~min}$, the supernatant was removed, and the bacterial pellet was resuspended in $10 \mathrm{mM} \mathrm{MgSO}_{4}$. The bacterial titer was adjusted to an optical density at $600 \mathrm{~nm}\left(\mathrm{OD}_{600}\right)$ of $1\left(1.8 \times 10^{9} \mathrm{CFU} \mathrm{ml}^{-1}\right)$, and $10 \mu \mathrm{l}$ of either bacterial inoculation

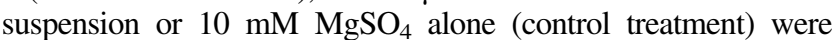
applied onto each seedling root on treatment plates. For growthcurve analysis, $B$. japonicum with an initial titer at $\mathrm{OD}_{600}$ of 0.05 was grown in $1 / 2 \mathrm{LB}$ liquid medium at $28^{\circ} \mathrm{C}$ with shaking at 100 $\mathrm{rpm}$, and with or without $0.1 \%$ DMSO or $1 \mu \mathrm{M}$ NPA. Spectrophotometric measurements were read at 4, 8, 12, 24, 48, and $72 \mathrm{~h}$.

Root colonization quantification was performed according to Allard-Massicotte et al. (2016), with modifications. At 5 days old, Col-0 seedlings were treated with $10 \mu \mathrm{l}$ of either $0.1 \%$ DMSO, $1 \mu \mathrm{M}$ NAA, or NC, followed by adding $10 \mu \mathrm{l}$ of bacterial suspension. At $0 \mathrm{dpi}$ ( $1 \mathrm{~h}$ following inoculation) and at 8 dpi, PR lengths were measured and roots were separated from their shoots. Roots were placed in tubes with $1 \mathrm{ml}$ of phosphatebuffered saline $\left(137 \mathrm{mM} \mathrm{NaCl}, 2.7 \mathrm{mM} \mathrm{KCl}, 10 \mathrm{mM} \mathrm{Na}_{2} \mathrm{HPO}_{4}\right.$,

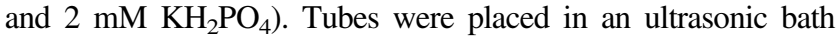
(Fisherbrand CPX3800) and sonicated to remove the bacteria with 1010 -s pulses on a low setting. Sonicated solutions were diluted and plated on 1/2 LB agar for CFU recovery counting.

\section{Root phenotypic analysis.}

PR length and emerged LR (greater than $0.5 \mathrm{~mm}$ ) number measurements were taken every 2 dpi for a total period of 8 days of cocultivation. A minimum of 10 seedlings was counted per treatment per replicate for each line. For LRP stages I to VII analysis, 4-day-old seedlings were treated with or without B. japonicum. At 4 dpi, the LRP stages were identified under microscopy, as defined by Torres-Martínez et al. (2019), and counted.

Auxin analog (Supplementary Fig. S1) LR number evaluation was performed by placing 5-day-old seedlings on 1/2 MS treatment plates with agar containing either $0.1 \%$ DMSO, $1 \mu \mathrm{M}$ NAA, $10 \mu \mathrm{M}$ IBA, or NC, followed by adding $10 \mu \mathrm{l}$ of either bacterial suspension or $10 \mathrm{mM} \mathrm{MgSO}_{4}$ (control treatment) to each root. Plants were grown for 8 days and LR were quantified under a dissecting microscope.

For inhibition of polar auxin transport, either NPA or DMSO (solvent-only control) were added to the treatment plate medium at a final concentration of $1 \mu \mathrm{M}$ or $0.1 \%$, respectively. Five-dayold seedlings were placed on the DMSO- or NPA-containing plates and $10 \mu \mathrm{l}$ of either $10 \mathrm{mM} \mathrm{MgSO}_{4}$ (control), bacterial suspension, culture filtrate, or $1 \mu \mathrm{M}$ NAA were topically added to each root. LR were counted and PR were measured at 0,4 , and 8 dpi.

Mean, standard error and Student's $t$ test significance were calculated in Microsoft Excel 2007. LR data were analyzed by Welch's ANOVA and Games-Howell post hoc analysis (with bacterial inoculation and noninoculation control as independent variables) using SPSS software (version 11.0; SPSS Inc., Chicago, IL, U.S.A.), $P<0.05$. 


\section{IAA quantification.}

Production of IAA by B. japonicum or USDA 110 LI was determined by cultivating the bacteria (starting concentration $\mathrm{OD}_{600}=0.05$ ) in $1 / 2 \mathrm{LB}$ or YM, respectively, with or without the addition of $2 \mathrm{mM}$ L-tryptophan. B. japonicum or USDA 110 LI were grown for 24 to $48 \mathrm{~h}$ at $28^{\circ} \mathrm{C}$ or for 5 days at $29^{\circ} \mathrm{C}$, respectively, with shaking at $100 \mathrm{rpm}$. Auxin content measurement was carried out following the protocol of Gordon and Weber (1951), with some modifications. Cultures were centrifuged at $14,000 \mathrm{rpm}$ for $5 \mathrm{~min}$; then, $0.5 \mathrm{ml}$ of the supernatant was combined with $0.75 \mathrm{ml}$ of Salkowski's reagent (1:30:50 [vol/vol/vol] of $0.5 \mathrm{M} \mathrm{FeCl}_{3}-\mathrm{H}_{2} \mathrm{O}-\mathrm{H}_{2} \mathrm{SO}_{4}$ ) and briefly vortexed. The mixture was incubated in the dark for $75 \mathrm{~min}$ at room temperature. Absorbance at $535 \mathrm{~nm}$ was measured on a spectrophotometer and the IAA content was calculated using an external standard curve generated with known concentrations of IAA.

\section{GUS staining and GFP analysis.}

Histochemical detection of GUS in the DR5:GUS reporter line was performed according to Zamioudis et al. (2013). Briefly, posttreatment seedlings were submerged in staining solution $(50$ $\mathrm{mM}$ sodium phosphate buffer [pH 7.0], $1 \mathrm{mM}$ 5-bromo-4-chloro3-indolyl- $\beta$-D-glucuronic acid sodium salt, $0.5 \mathrm{mM}$ ferricyanide, $0.5 \mathrm{mM}$ ferrocyanide, and $10 \mathrm{mM}$ EDTA) at $37^{\circ} \mathrm{C}$ for $6 \mathrm{~h}$, then incubated in $95 \% \mathrm{EtOH}$ overnight. Imaging was performed using a Leica DM2500 LED optical microscope, a Leica DMC4500 digital camera, and Leica Application Suite X software (Leica Microsystems, Wetzlar, Germany).

PIN3:GFP, PIN7:GFP, and ABCB19:GFP seedlings were treated at 6 days old with either $10 \mathrm{mM} \mathrm{MgSO}_{4}$ or $B$. japonicum for $12 \mathrm{~h}$ ( $24 \mathrm{~h}$ for Supplementary Fig. S9) before incubation in propidium iodide at $10 \mathrm{mg} / \mathrm{ml}$ for $10 \mathrm{~s}$, followed by a brief water rinse. Seedlings were mounted in water on slides with coverslips and imaged using a Leica SP5 confocal microscope and Leica Application Suite X software.

\section{RNA-seq and qRT-PCR.}

Total RNA was extracted from 21-day-old $A$. thaliana seedling roots at $14 \mathrm{dpi}$, according to the manufacturer's protocol (GeneJET Plant RNA Purification Kit; Thermo Scientific, Madison, WI, U.S.A.).

For RNA-seq, the RNA was processed (74204 QIAGEN and AM1907 Invitrogen) and libraries were prepared with the NEBNext Ultra Directional RNA Library Prep Kit for Illumina by following the manufacturer's instruction (E7490S, E7335S, and E7420S; New England Biolabs). Libraries were pooled and sequenced on an Illumina NextSeq 500 platform (Illumina, San Diego, CA, U.S.A.) at the University of California-Riverside Genomics Core Facility.

The program Salmon was used to process raw RNA-seq data to quantify the transcript data from all samples (Patro et al. 2017). The quantified data were analyzed using the $\mathrm{R}$ program ThreeDRNA (Calixto et al. 2018; Guo et al. 2021; R Core Team 2020). Briefly, quantified transcript data were uploaded into ThreeDRNA using the integrated tximport program (v. 1.18.0) and the default setting lengthScaledTPM method (Soneson et al. 2016). Low-quality expression data were filtered using the default count per million reads cutoff of 1 and sample number cutoff of 1. The processed data were used to generate a PCA graph using the RUVr method of removing batch effects from the data. Transcriptome data were normalized using the weighted trimmed mean of $\mathrm{M}$ values in ThreeDRNA. The data were statistically analyzed using the limma-voom pipeline recommended by ThreeDRNA, which balances outliers in the data that may occur from sample quality differences (Law et al. 2014; Ritchie et al. 2015). For downstream plots, the data were filtered to only include samples with $P$ values $\leq 0.05$ and $\log _{2} \mathrm{FC} \geq 1$ between the noninoculated controls and samples inoculated with B. japonicum. The filtered data were used to generate a heatmap using the program shinyheatmap (Khomtchouk et al. 2017). To identify auxin-related genes within our (adjusted $P$ value $<0.05$ ) RNAseq data for the heatmap, gene ontology (GO) terminology was compiled at the Panther Geneontology website with the annotation version GO database (released 2018-10-09), analysis type PANTHER Overrepresentation Test (released 2020-07-28), and test type GO biological process complete with Fisher's Exact false discovery rate (FDR) multiple test correction displaying only results with FDR $<0.05$.

For each qRT-PCR sample, genomic DNA was removed from $1 \mu \mathrm{g}$ of total RNA prior to RT into first-strand cDNA (iScript Kit; Bio-Rad, Hercules, CA, U.S.A.) according to the manufacturer's protocol. The first-strand cDNA was used for SYBR greenmonitored qRT-PCR (Bio-Rad CFX). Primer sequences for PIN1, PIN2, PIN3, PIN7, ABCB4, and $A B C B 19$ have been described (Terasaka et al. 2005; H. Z. Wang et al. 2015; Xi et al. 2016; Yang et al. 2013). qRT-PCR analysis was performed using the Bio-Rad CFX Maestro Real-Time PCR System.

\section{ACKNOWLEDGMENTS}

We thank T. Missihoun for assistance with GH3.3 gene expression.

\section{AUTHOR-RECOMMENDED INTERNET RESOURCE}

Panther Geneontology: http://go.pantherdb.org

\section{LITERATURE CITED}

Abas, L., Kolb, M., Stadlmann, J., Janacek, D. P., Lukic, K., Schwechheimer, C., Sazanov, L. A., Mach, L., Friml, J., and Hammes, U. Z. 2021. Naphthylphthalamic acid associates with and inhibits PIN auxin transporters. Proc. Natl. Acad. Sci. U.S.A. 118:e2020857118.

Allard-Massicotte, R., Tessier, L., Lécuyer, F., Lakshmanan, V., Lucier, J. F., Garneau, D., Caudwell, L., Vlamakis, H., Bais, H. P., and Beauregard, P. B. 2016. Bacillus subtilis early colonization of Arabidopsis thaliana roots involves multiple chemotaxis receptors. MBio 7: e01664-16.

Asari, S., Tarkowská, D., Rolčík, J., Novák, O., Palmero, D. V., Bejai, S., and Meijer, J. 2017. Analysis of plant growth-promoting properties of Bacillus amyloliquefaciens UCMB5113 using Arabidopsis thaliana as host plant. Planta 245:15-30.

Backer, R., Rokem, J. S., Ilangumaran, G., Lamont, J., Praslickova, D., Ricci, E., Subramanian, S., and Smith, D. L. 2018. Plant growthpromoting rhizobacteria: Context, mechanisms of action, and roadmap to commercialization of biostimulants for sustainable agriculture. Front. Plant Sci. 9:1473.

Bailly, A., Groenhagen, U., Schulz, S., Geisler, M., Eberl, L., and Weisskopf, L. 2014. The inter-kingdom volatile signal indole promotes root development by interfering with auxin signalling. Plant J. 80:758-771.

Barbez, E., Kubeš, M., Rolčík, J., Béziat, C., Pěnčík, A., Wang, B., Rosquete, M. R., Zhu, J., Dobrev, P. I., Lee, Y., Zažímalovà, E., Petrášek, J., Geisler, M., Friml, J., and Kleine-Vehn, J. 2012. A novel putative auxin carrier family regulates intracellular auxin homeostasis in plants. Nature 485:119-122.

Barrada, A., Montané, M. H., Robaglia, C., and Menand, B. 2015. Spatial regulation of root growth: Placing the plant TOR pathway in a developmental perspective. Int. J. Mol. Sci. 16:19671-19697.

Benková, E., Michniewicz, M., Sauer, M., Teichmann, T., Seifertová, D., Jürgens, G., and Friml, J. 2003. Local, efflux-dependent auxin gradients as a common module for plant organ formation. Cell 115:591-602.

Blakeslee, J. J., Bandyopadhyay, A., Lee, O. R., Mravec, J., Titapiwatanakun, B., Sauer, M., Makam, S. N., Cheng, Y., Bouchard, R., Adamec, J., Geisler, M., Nagashima, A., Sakai, T., Martinoia, E., Friml, J., Peer, W. A., and Murphy, A. S. 2007. Interactions among PINFORMED and P-glycoprotein auxin transporters in Arabidopsis. Plant Cell 19:131-147.

Blilou, I., Xu, J., Wildwater, M., Willemsen, V., Paponov, I., Friml, J., Heidstra, R., Aida, M., Palme, K., and Scheres, B. 2005. The PIN auxin efflux facilitator network controls growth and patterning in Arabidopsis roots. Nature 433:39-44. 
Boerjan, W., Cervera, M. T., Delarue, M., Beeckman, T., Dewitte, W., Bellini, C., Caboche, M., Van Onckelen, H., Van Montagu, M., and Inzé, D. 1995. Superroot, a recessive mutation in Arabidopsis, confers auxin overproduction. Plant Cell 7:1405-1419.

Boiero, L., Perrig, D., Masciarelli, O., Penna, C., Cassán, F., and Luna, V. 2007. Phytohormone production by three strains of Bradyrhizobium japonicum and possible physiological and technological implications. Appl. Microbiol. Biotechnol. 74:874-880.

Calixto, C. P. G., Guo, W., James, A. B., Tzioutziou, N. A., Entizne, J. C., Panter, P. E., Knight, H., Nimmo, H. G., Zhang, R., and Brown, J. W. S. 2018. Rapid and dynamic alternative splicing impacts the Arabidopsis cold response transcriptome. Plant Cell 30:1424-1444.

Casimiro, I., Marchant, A., Bhalerao, R. P., Beeckman, T., Dhooge, S. Swarup, R., Graham, N., Inzé, D., Sandberg, G., Casero, P. J., and Bennett, M. 2001. Auxin transport promotes Arabidopsis lateral root initiation. Plant Cell 13:843-852.

Cavallari, N., Artner, C., and Benkova, E. 2021. Auxin-regulated lateral root organogenesis. Cold Spring Harb. Perspect. Biol. 13:a039941.

Chen, Q., Liu, Y., Maere, S., Lee, E., Van Isterdael, G., Xie, Z., Xuan, W., Lucas, J., Vassileva, V., Kitakura, S., Marhavý, P., Wabnik, K., Geldner, N., Benková, E., Le, J., Fukaki, H., Grotewold, E., Li, C., Friml, J., Sack, F., Beeckman, T., and Vanneste, S. 2015. A coherent transcriptional feed-forward motif model for mediating auxin-sensitive PIN3 expression during lateral root development. Nat. Commun. 6:8821.

Cho, M., and Cho, H. T. 2013. The function of ABCB transporters in auxin transport. Plant Signal. Behav. 8:e22990.

Delbarre, A., Muller, P., Imhoff, V., and Guern, J. 1996. Comparison of mechanisms controlling uptake and accumulation of 2,4-dichlorophenoxy acetic acid, naphthalene-1-acetic acid, and indole-3-acetic acid in suspension-cultured tobacco cells. Planta 198:532-541.

Di Mambro, R., De Ruvo, M., Pacifici, E., Salvi, E., Sozzani, R., Benfey, P. N., Busch, W., Novak, O., Ljung, K., Di Paola, L., Marée, A. F. M., Costantino, P., Grieneisen, V. A., and Sabatini, S. 2017. Auxin minimum triggers the developmental switch from cell division to cell differentiation in the Arabidopsis root. Proc. Natl. Acad. Sci. U.S.A. 114:E7641-E7649.

Dobbelaere, S., Croonenborghs, A., Thys, A., Vande Broek, A., and Vanderleyden, J. 1999. Phytostimulatory effect of Azospirillum brasilense wild type and mutant strains altered in IAA production on wheat. Plant Soil 212:153-162.

Du, Y., and Scheres, B. 2018. Lateral root formation and the multiple roles of auxin. J. Exp. Bot. 69:155-167.

Dubrovsky, J. G., Sauer, M., Napsucialy-Mendivil, S., Ivanchenko, M. G., Friml, J., Shishkova, S., Celenza, J., and Benková, E. 2008 Auxin acts as a local morphogenetic trigger to specify lateral root founder cells. Proc. Natl. Acad. Sci. U.S.A. 105:8790-8794

Friml, J., Benková, E., Blilou, I., Wiśniewska, J., Hamann, T., Ljung, K., Woody, S., Sandberg, G., Scheres, B., Jürgens, G., and Palme, K. 2002. AtPIN4 mediates sink-driven auxin gradients and root patterning in Arabidopsis. Cell 108:661-673.

Fukaki, H., and Tasaka, M. 2009. Hormone interactions during lateral root formation. Plant Mol. Biol. 69:437-449.

Gachomo, E. W., Kefela, T., Houngnandan, P., Baba-Moussa, L., and Kotchoni, S. O. 2014. Bradyrhizobium 434 japonicum IRAT FA3 increases biomass, yield and drought tolerance in plants. J. Biol. Nat. 1: $12-23$

Geisler, M., Aryal, B., di Donato, M., and Hao, P. 2017. A critical view on $\mathrm{ABC}$ transporters and their interacting partners in auxin transport. Plant Cell Physiol. 58:1601-1614.

Gordon, S. A., and Weber, R. P. 1951. Colorimetric estimation of indoleacetic acid. Plant Physiol. 26:192-195.

Grieneisen, V. A., Xu, J., Marée, A. F., Hogeweg, P., and Scheres, B. 2007. Auxin transport is sufficient to generate a maximum and gradient guiding root growth. Nature 449:1008-1013.

Grunewald, W., van Noorden, G., Van Isterdael, G., Beeckman, T., Gheysen, G., and Mathesius, U. 2009. Manipulation of auxin transport in plant roots during Rhizobium symbiosis and nematode parasitism. Plant Cell 21:2553-2562.

Guo, W., Tzioutziou, N. A., Stephen, G., Milne, I., Calixto, C. P. G., Waugh, R., Brown, J., and Zhang, R. 2021. 3D RNA-seq: A powerful and flexible tool for rapid and accurate differential expression and alternative splicing analysis of RNA-seq data for biologists. RNA Biol. 18:1574-1587.

Guo, X., Lu, W., Ma, Y., Qin, Q., and Hou, S. 2013. The BIG gene is required for auxin-mediated organ growth in Arabidopsis. Planta 237: 1135-1147.

Gutknecht, J., and Walter, A. 1980. Transport of auxin (indoleacetic acid) through lipid bilayer membranes. J. Membr. Biol. 56:65-72
Hazak, O., Bloch, D., Poraty, L., Sternberg, H., Zhang, J., Friml, J., and Yalovsky, S. 2010. A rho scaffold integrates the secretory system with feedback mechanisms in regulation of auxin distribution. PLoS Biol. 8:e1000282.

Hodge, A., Berta, G., Doussan, C., Merchan, F., and Crespi, M. 2009. Plant root growth, architecture and function. Plant Soil 321:153-187.

Jenness, M. K., Tayengwa, R., and Murphy, A. S. 2020. An ATP-binding cassette transporter, ABCB19, regulates leaf position and morphology during Phototropin1-mediated blue light responses. Plant Physiol. 184 1601-1612.

Jiménez-Vázquez, K. R., García-Cárdenas, E., Barrera-Ortiz, S., OrtizCastro, R., Ruiz-Herrera, L. F., Ramos-Acosta, B. P., Coria-Arellano, J. L., Sáenz-Mata, J., and López-Bucio, J. 2020. The plant beneficial rhizobacterium Achromobacter sp. 5B1 influences root development through auxin signaling and redistribution. Plant J. 103:1639-1654.

Jozef, L., Katarzyna, R., Christian, L., and Eva, Z. 2017. Polar auxin transport. eLS, John Wiley \& Sons, Ltd.

Kamilova, F., Kravchenko, L. V., Shaposhnikov, A. I., Azarova, T., Makarova, N., and Lugtenberg, B. 2006. Organic acids, sugars, and L-tryptophane in exudates of vegetables growing on stonewool and their effects on activities of rhizosphere bacteria. Mol. Plant-Microbe Interact. 19:250-256

Khomtchouk, B. B., Hennessy, J. R., and Wahlestedt, C. 2017. shinyheatmap: Ultra fast low memory heatmap web interface for big data genomics. PLoS One 12:e0176334.

Kleine-Vehn, J., Dhonukshe, P., Sauer, M., Brewer, P. B., Wiśniewska, J., Paciorek, T., Benková, E., and Friml, J. 2008. ARF GEF-dependent transcytosis and polar delivery of PIN auxin carriers in Arabidopsis. Curr. Biol. 18:526-531.

Kramer, E. M., and Bennett, M. J. 2006. Auxin transport: A field in flux. Trends Plant Sci. 11:382-386.

Křeček, P., Ski̊pa, P., Libus, J., Naramoto, S., Tejos, R., Friml, J., and Zazímalová, E. 2009. The PIN-FORMED (PIN) protein family of auxin transporters. Genome Biol. 10:249.

Kubeš, M., Yang, H., Richter, G. L., Cheng, Y., Młodzińska, E., Wang, X., Blakeslee, J. J., Carraro, N., Petrášek, J., Zažímalová, E., Hoyerová, K., Peer, W. A., and Murphy, A. S. 2012. The Arabidopsis concentration-dependent influx/efflux transporter ABCB4 regulates cellular auxin levels in the root epidermis. Plant J. 69:640-654.

Kuykendall, L. D., and Elkan, G. H. 1976. Rhizobium japonicum derivatives differing in nitrogen-fixing efficiency and carbohydrate utilization. Appl. Environ. Microbiol. 32:511-519.

Laskowski, M., Grieneisen, V. A., Hofhuis, H., Hove, C. A., Hogeweg, P., Marée, A. F., and Scheres, B. 2008. Root system architecture from coupling cell shape to auxin transport. PLoS Biol. 6:e307.

Laskowski, M., and ten Tusscher, K. H. 2017. Periodic lateral root priming: What makes it tick? Plant Cell 29:432-444.

Lavenus, J., Goh, T., Guyomarc'h, S., Hill, K., Lucas, M., Voß, U., Kenobi, K., Wilson, M. H., Farcot, E., Hagen, G., Guilfoyle, T. J., Fukaki, H., Laplaze, L., and Bennett, M. J. 2015. Inference of the Arabidopsis lateral root gene regulatory network suggests a bifurcation mechanism that defines primordia flanking and central zones. Plant Cell 27:1368-1388

Law, C. W., Chen, Y., Shi, W., and Smyth, G. K. 2014. voom: Precision weights unlock linear model analysis tools for RNA-seq read counts Genome Biol. 15:R29.

Lewis, D. R., Miller, N. D., Splitt, B. L., Wu, G., and Spalding, E. P 2007. Separating the roles of acropetal and basipetal auxin transport on gravitropism with mutations in two Arabidopsis multidrug resistance-like ABC transporter genes. Plant Cell 19:1838-1850.

Lewis, D. R., Negi, S., Sukumar, P., and Muday, G. K. 2011. Ethylene inhibits lateral root development, increases IAA transport and expression of PIN3 and PIN7 auxin efflux carriers. Development 138:34853495

Leyser, O. 2006. Dynamic integration of auxin transport and signalling. Curr. Biol. 16:R424-R433.

Li, G., Song, H., Li, B., Kronzucker, H. J., and Shi, W. 2015. Auxin resistant1 and PIN-FORMED2 protect lateral root formation in Arabidopsis under iron stress. Plant Physiol. 169:2608-2623.

Loper, J. E., and Schroth, M. N. 1986. Influence of bacterial sources on indole-3-acetic acid on root elongation of sugar beet. Phytopathology 76:386-389.

López-Bucio, J., Campos-Cuevas, J. C., Hernández-Calderón, E., Velásquez-Becerra, C., Farías-Rodríguez, R., Macías-Rodríguez, L. I., and Valencia-Cantero, E. 2007. Bacillus megaterium rhizobacteria promote growth and alter root-system architecture through an auxin- and ethylene-independent signaling mechanism in Arabidopsis thaliana. Mol. Plant-Microbe Interact. 20:207-217. 
Marhavý, P., Vanstraelen, M., De Rybel, B., Zhaojun, D., Bennett, M. J., Beeckman, T., and Benková, E. 2013. Auxin reflux between the endodermis and pericycle promotes lateral root initiation. EMBO J. 32:149158.

Minamisawa, K., and Fukai, K. 1991. Production of indole-3-acetic acid by Bradyrhizobium japonicum: A correlation with genotype grouping and rhizobitoxine production. Plant Cell Physiol. 32:1-9.

Minamisawa, K., Ogawa, K., Fukuhara, H., and Koga, J. 1996. Indolepyruvate pathway for indole-3-acetic acid biosynthesis in Bradyrhizobium elkanii. Plant Cell Physiol. 37:449-453.

Mohanta, T. K., Bashir, T., Hashem, A., Abd_Allah, E. F., Khan, A. L., and Al-Harrasi, A. S. 2018. Molecular players of auxin transport systems: Advances in genomic and molecular events. J. Plant Interact. 13: 483-495.

Motte, H., Vanneste, S., and Beeckman, T. 2019. Molecular and environmental regulation of root development. Annu. Rev. Plant Biol. 70:465488

Muday, G. K., and DeLong, A. 2001. Polar auxin transport: Controlling where and how much. Trends Plant Sci. 6:535-542.

Müller, A., Guan, C., Gälweiler, L., Tänzler, P., Huijser, P., Marchant, A., Parry, G., Bennett, M., Wisman, E., and Palme, K. 1998. AtPIN2 defines a locus of Arabidopsis for root gravitropism control. EMBO J. 17:6903-6911.

Ng, J. L. P., Perrine-Walker, F., Wasson, A. P., and Mathesius, U. 2015. The control of auxin transport in parasitic and symbiotic root-microbe interactions. Plants 4:606-643.

Noh, B., Bandyopadhyay, A., Peer, W. A., Spalding, E. P., and Murphy, A. S. 2003. Enhanced gravi- and phototropism in plant $m d r$ mutants mislocalizing the auxin efflux protein PIN1. Nature 423:999-1002.

Noh, B., Murphy, A. S., and Spalding, E. P. 2001. Multidrug resistancelike genes of Arabidopsis required for auxin transport and auxinmediated development. Plant Cell 13:2441-2454.

Overvoorde, P., Fukaki, H., and Beeckman, T. 2010. Auxin control of root development. Cold Spring Harb. Perspect. Biol. 2:a001537.

Paciorek, T., Zazímalová, E., Ruthardt, N., Petrásek, J., Stierhof, Y. D., Kleine-Vehn, J., Morris, D. A., Emans, N., Jürgens, G., Geldner, N., and Friml, J. 2005. Auxin inhibits endocytosis and promotes its own efflux from cells. Nature 435:1251-1256.

Paponov, I. A., Teale, W. D., Trebar, M., Blilou, I., and Palme, K. 2005 The PIN auxin efflux facilitators: Evolutionary and functional perspectives. Trends Plant Sci. 10:170-177.

Patro, R., Duggal, G., Love, M. I., Irizarry, R. A., and Kingsford, C. 2017. Salmon provides fast and bias-aware quantification of transcript expression. Nat. Methods 14:417-419.

Péret, B., Middleton, A. M., French, A. P., Larrieu, A., Bishopp, A., Njo, M., Wells, D. M., Porco, S., Mellor, N., Band, L. R., Casimiro, I. Kleine-Vehn, J., Vanneste, S., Sairanen, I., Mallet, R., Sandberg, G., Ljung, K., Beeckman, T., Benková, E., Friml, J., Kramer, E., King, J. R., De Smet, I., Pridmore, T., Owen, M., and Bennett, M. J. 2013. Sequential induction of auxin efflux and influx carriers regulates lateral root emergence. Mol. Syst. Biol. 9:699.

Petrásek, J., and Friml, J. 2009. Auxin transport routes in plant development. Development 136:2675-2688.

Qu, Y., Wang, Q., Guo, J., Wang, P., Song, P., Jia, Q., Zhang, X., Kudla, J., Zhang, W., and Zhang, Q. 2017. Peroxisomal $\mathrm{CuAO} \zeta$ and its product $\mathrm{H}_{2} \mathrm{O}_{2}$ regulate the distribution of auxin and IBA-dependent lateral root development in Arabidopsis. J. Exp. Bot. 68:4851-4867.

Rahman, A., Bannigan, A., Sulaman, W., Pechter, P., Blancaflor, E. B., and Baskin, T. I. 2007. Auxin, actin and growth of the Arabidopsis thaliana primary root. Plant J. 50:514-528.

R Core Team. 2020. R: A Language and Environment for Statistical Computing. R Foundation for Statistical Computing, Vienna, Austria. https://www.r-project.org/

Ritchie, M. E., Phipson, B., Wu, D., Hu, Y., Law, C. W., Shi, W., and Smyth, G. K. 2015. limma powers differential expression analyses for RNA-sequencing and microarray studies. Nucleic Acids Res. 43:e47.

Rogg, L. E., Lasswell, J., and Bartel, B. 2001. A gain-of-function mutation in IAA28 suppresses lateral root development. Plant Cell 13:465-480.

Rojas-Pierce, M., Titapiwatanakun, B., Sohn, E. J., Fang, F., Larive, C. K., Blakeslee, J., Cheng, Y., Cutler, S. R., Peer, W. A., Murphy, A. S., and Raikhel, N. V. 2007. Arabidopsis P-glycoprotein 19 participates in the inhibition of gravitropism by gravacin. Chem. Biol. 14:1366-1376.

Ruiz Rosquete, M., Waidmann, S., and Kleine-Vehn, J. 2018. PIN7 auxin carrier has a preferential role in terminating radial root expansion in Arabidopsis thaliana. Int. J. Mol. Sci. 19:1238.

Ryu, C. M., Farag, M. A., Hu, C. H., Reddy, M. S., Wei, H. X., Paré, P. W., and Kloepper, J. W. 2003. Bacterial volatiles promote growth in Arabidopsis. Proc. Natl. Acad. Sci. U.S.A. 100:4927-4932.
Sauer, M., and Kleine-Vehn, J. 2019. PIN-FORMED and PIN-LIKES auxin transport facilitators. Development 146:dev168088.

Semeradova, H., Montesinos, J. C., and Benková, E. 2020. All roads lead to auxin: Post-translational regulation of auxin transport by multiple hormonal pathways. Plant Commun. 1:100048.

Shah, V., and Subramaniam, S. 2018. Bradyrhizobium japonicum USDA110: A representative model organism for studying the impact of pollutants on soil microbiota. Sci. Total Environ. 624:963-967.

Shi, C. L., Park, H. B., Lee, J. S., Ryu, S., and Ryu, C. M. 2010. Inhibition of primary roots and stimulation of lateral root development in Arabidopsis thaliana by the rhizobacterium Serratia marcescens 90-166 is through both auxin-dependent and -independent signaling pathways. Mol. Cells 29:251-258.

Simon, S., Kubeš, M., Baster, P., Robert, S., Dobrev, P. I., Friml, J., Petrášek, J., and Zažímalová, E. 2013. Defining the selectivity of processes along the auxin response chain: A study using auxin analogues. New Phytol. 200:1034-1048.

Soneson, C., Love, M. I., and Robinson, M. D. 2016. Differential analyses for RNA-seq: Transcript-level estimates improve gene-level inferences. F1000 Res. 4:1521.

Spaepen, S., Bossuyt, S., Engelen, K., Marchal, K., and Vanderleyden, J. 2014. Phenotypical and molecular responses of Arabidopsis thaliana roots as a result of inoculation with the auxin-producing bacterium Azospirillum brasilense. New Phytol. 201:850-861.

Spaepen, S., Vanderleyden, J., and Remans, R. 2007. Indole-3-acetic acid in microbial and microorganism-plant signaling. FEMS Microbiol. Rev. 31:425-448.

Stoeckle, D., Thellmann, M., and Vermeer, J. E. 2018. Breakout-lateral root emergence in Arabidopsis thaliana. Curr. Opin. Plant Biol. 41:67-72.

Sukumar, P., Legué, V., Vayssières, A., Martin, F., Tuskan, G. A., and Kalluri, U. C. 2013a. Involvement of auxin pathways in modulating root architecture during beneficial plant-microorganism interactions. Plant Cell Environ. 36:909-919.

Sukumar, P., Maloney, G. S., and Muday, G. K. 2013b. Localized induction of the ATP-binding cassette B19 auxin transporter enhances adventitious root formation in Arabidopsis. Plant Physiol. 162:1392 1405

Tanaka, H., Dhonukshe, P., Brewer, P. B., and Friml, J. 2006. Spatiotemporal asymmetric auxin distribution: A means to coordinate plant development. Cell. Mol. Life Sci. 63:2738-2754.

Teale, W., and Palme, K. 2018. Naphthylphthalamic acid and the mechanism of polar auxin transport. J. Exp. Bot. 69:303-312.

Terasaka, K., Blakeslee, J. J., Titapiwatanakun, B., Peer, W. A., Bandyopadhyay, A., Makam, S. N., Lee, O. R., Richards, E. L. Murphy, A. S., Sato, F., and Yazaki, K. 2005. PGP4, an ATP binding cassette P-glycoprotein, catalyzes auxin transport in Arabidopsis thaliana roots. Plant Cell 17:2922-2939.

Titapiwatanakun, B., Blakeslee, J. J., Bandyopadhyay, A., Yang, H., Mravec, J., Sauer, M., Cheng, Y., Adamec, J., Nagashima, A., Geisler, M., Sakai, T., Friml, J., Peer, W. A., and Murphy, A. S. 2009. ABCB19/PGP19 stabilises PIN1 in membrane microdomains in Arabidopsis. Plant J. 57:27-44.

Torres, D., Benavidez, I., Donadio, F., Mongiardini, E., Rosas, S., Spaepen, S., Vanderleyden, J., Pěnčík, A., Novák, O., Strnad, M. Frébortová, J., and Cassán, F. 2018. New insights into auxin metabolism in Bradyrhizobium japonicum. Res. Microbiol. 169:313-323.

Torres-Martínez, H. H., Rodríguez-Alonso, G., Shishkova, S., and Dubrovsky, J. G. 2019. Lateral root primordium morphogenesis in angiosperms. Front. Plant Sci. 10:206.

Ulmasov, T., Murfett, J., Hagen, G., and Guilfoyle, T. J. 1997. Aux/IAA proteins repress expression of reporter genes containing natural and highly active synthetic auxin response elements. Plant Cell 9:1963-1971.

Vacheron, J., Desbrosses, G., Bouffaud, M. L., Touraine, B., MoënneLoccoz, Y., Muller, D., Legendre, L., Wisniewski-Dyé, F., and Prigent-Combaret, C. 2013. Plant growth-promoting rhizobacteria and root system functioning. Front. Plant Sci. 4:356.

Vanneste, S., De Rybel, B., Beemster, G. T., Ljung, K., De Smet, I., Van Isterdael, G., Naudts, M., Iida, R., Gruissem, W., Tasaka, M., Inzé, D. Fukaki, H., and Beeckman, T. 2005. Cell cycle progression in the pericycle is not sufficient for SOLITARY ROOT/IAA14-mediated lateral root initiation in Arabidopsis thaliana. Plant Cell 17:3035-3050.

Vieten, A., Vanneste, S., Wisniewska, J., Benková, E., Benjamins, R., Beeckman, T., Luschnig, C., and Friml, J. 2005. Functional redundancy of PIN proteins is accompanied by auxin-dependent cross-regulation of PIN expression. Development 132:4521-4531.

Waidmann, S., Sarkel, E., and Kleine-Vehn, J. 2020. Same same, but different: Growth responses of primary and lateral roots. J. Exp. Bot. 71 2397-2411. 
Wang, H. Z., Yang, K. Z., Zou, J. J., Zhu, L. L., Xie, Z. D., Morita, M. T., Tasaka, M., Friml, J., Grotewold, E., Beeckman, T., Vanneste, S., Sack, F., and Le, J. 2015. Transcriptional regulation of PIN genes by FOUR LIPS and MYB88 during Arabidopsis root gravitropism. Nat. Commun. 6:8822.

Wang, J., Zhang, Y., Li, Y., Wang, X., Nan, W., Hu, Y., Zhang, H., Zhao, C., Wang, F., Li, P., Shi, H., and Bi, Y. 2015. Endophytic microbes Bacillus sp. LZR216-regulated root development is dependent on polar auxin transport in Arabidopsis seedlings. Plant Cell Rep. 34:1075-1087.

Woodward, A. W., and Bartel, B. 2005. Auxin: Regulation, action, and interaction. Ann. Bot. 95:707-735.

Wu, G., Lewis, D. R., and Spalding, E. P. 2007. Mutations in Arabidopsis multidrug resistance-like $\mathrm{ABC}$ transporters separate the roles of acropetal and basipetal auxin transport in lateral root development. Plant Cell 19:1826-1837.

Xi, W., Gong, X., Yang, Q., Yu, H., and Liou, Y. C. 2016. Pin1At regulates PIN1 polar localization and root gravitropism. Nat. Commun. 7: 10430.
Yang, H., Richter, G. L., Wang, X., Młodzińska, E., Carraro, N., Ma, G., Jenness, M., Chao, D. Y., Peer, W. A., and Murphy, A. S. 2013. Sterols and sphingolipids differentially function in trafficking of the Arabidopsis ABCB19 auxin transporter. Plant J. 74:37-47.

Zamioudis, C., Mastranesti, P., Dhonukshe, P., Blilou, I., and Pieterse, C. M. 2013. Unraveling root developmental programs initiated by beneficial Pseudomonas spp. bacteria. Plant Physiol. 162:304-318.

Zažímalová, E., Murphy, A. S., Yang, H., Hoyerová, K., and Hosek, P. 2010. Auxin transporters-Why so many? Cold Spring Harb. Perspect. Biol. 2:a001552.

Zhang, R. X., Li, S., He, J., and Liang, Y. K. 2019. BIG regulates sugar response and $\mathrm{C} / \mathrm{N}$ balance in Arabidopsis. Plant Signal. Behav. 14: 1669418.

Zhang, Y., Rodriguez, L., Li, L., Zhang, X., and Friml, J. 2020. Functional innovations of PIN auxin transporters mark crucial evolutionary transitions during rise of flowering plants. Sci. Adv. 6:eabc8895.

Zhou, J. J., and Luo, J. 2018. The PIN-FORMED auxin efflux carriers in plants. Int. J. Mol. Sci. 19:2759. 